\title{
Role of MicroRNAs in Parkinson's Disease
}

\author{
Suh Yee Goh ${ }^{1}$, Yin Xia Chao ${ }^{2,3,4, *}$, Shaikali Thameem Dheen ${ }^{1}$, Eng-King Tan ${ }^{2,3,5, *}$ and \\ Samuel Sam-Wah Tay ${ }^{1, *}$
}

1 Department of Anatomy, Yong Loo Lin School of Medicine, National University of Singapore, 4 Medical Drive, Singapore 117594, Singapore; e0054068@u.nus.edu (S.Y.G.); anthead@nus.edu.sg (S.T.D.)

2 National Neuroscience Institute, 11 Jalan Tan Tock Seng, Singapore 308433, Singapore

3 Department of Neurology, Singapore General Hospital, Outram Road, Singapore 169608, Singapore

4 Medical Education, Research and Evaluation (MERE) department, Duke-NUS Medical School, 8 College Rd, Singapore 169857, Singapore

5 Neuroscience and Behavioral Disorders (NBD) department, Duke-NUS Medical School, 8 College Rd, Singapore 169857, Singapore

* Correspondence: chao.yinxia@singhealth.com.sg (Y.X.C.); tan.eng.king@singhealth.com.sg (E.-K.T.); anttaysw@nus.edu.sg (S.S.-W.T.); Tel.: +65-63-214-073 (Y.X.C.); +65-63-214-006 (E.-K.T.); +65-65-163-210 (S.S.-W.T.)

Received: 18 October 2019; Accepted: 8 November 2019; Published: 12 November 2019

\begin{abstract}
Parkinson's disease (PD) is a disabling neurodegenerative disease that manifests with resting tremor, bradykinesia, rigidity and postural instability. Since the discovery of microRNAs (miRNAs) in 1993, miRNAs have been shown to be important biological molecules involved in diverse processes to maintain normal cellular functions. Over the past decade, many studies have reported dysregulation of miRNA expressions in PD. Here, we identified 15 miRNAs from 34 reported screening studies that demonstrated dysregulation in the brain and/or neuronal models, cerebrospinal fluid (CSF) and blood. Specific miRNAs-of-interest that have been implicated in PD pathogenesis include miR-30, miR-29, let-7, miR-485 and miR-26. However, there are several challenges and limitations in drawing definitive conclusions due to the small sample size in clinical studies, varied laboratory techniques and methodologies and their incomplete penetrance of the blood-brain barrier. Developing an optimal delivery system and unravelling druggable targets of miRNAs in both experimental and human models and clinical validation of the results may pave way for novel therapeutics in PD.
\end{abstract}

Keywords: Parkinson's disease; microRNAs; review

\section{Introduction}

Parkinson's disease (PD) is the most common movement disorder in the aging population. An estimated prevalence of $1 \%$ of people above 60 years old suffer from PD [1]. PD involves a progressive loss of neurons in the brain, especially the loss of dopaminergic (DA) neurons in the substantia nigra pars compacta $(\mathrm{SNc})$. When more than $50 \%$ to $70 \%$ of DA neurons are lost, resulting in the corresponding decrease in dopamine neurotransmitter production and signaling, this can manifest as motor dysfunctions and clinical symptoms such as resting tremor, bradykinesia, rigidity and postural instability [2]. In addition, intracellular inclusions, known as Lewy bodies, which are enriched with the aggregated $\alpha$-synuclein protein ( $\alpha$-syn), are also often detected in the neurons of PD patients and are suggested to impair pathways such as vesicle trafficking or activating neuroinflammation [3]. In the Braak staging hypothesis, it was proposed that PD starts as a synucleinopathy in lower non-dopminergic structures of the brainstem and spreads rostrally to affect the SNc in the later stage of PD [4]. Aside from the SNc, PD-specific cell loss has also been reported in the ventral tegmental area, amygdala, 
and dorsal motor nucleus of the vagus nerve, hypothalamus, cortex, thalamus and many other brain regions [5]. It has been suggested that the loss of neurons in these areas may also contribute to the motor dysfunctions observed in PD as well as other non-related motor symptoms such as depression, anxiety and sleep disorders [6]. Therefore, in this review, we have considered studies that investigated not only the SNc, but also other brain regions.

Currently, clinical treatments available for PD are mainly symptomatic which include medications such as Levodopa, dopamine agonists, catechol-O-methyl transferase (COMT) inhibitors and monoamine oxidase B inhibitors and non-pharmacological interventions such as deep brain stimulation [7,8]. While these treatments alleviate the motor symptoms of PD, they are not neuroprotective in nature and cannot stop disease progression or reverse the neurodegeneration. Moreover, long-term usage can cause serious side effects such as dyskinesia [9]. Therefore, many efforts have gone into understanding the pathogenesis of $\mathrm{PD}$ in order to develop neuroprotective treatments. Both environmental and genetic factors such as $\alpha$-synuclein (SNCA) and leucine-rich repeat kinase 2 (LRRK2) mutations have been reported to contribute to PD development through regulating the mitochondrial function in DA neurons $[10,11]$. Blood-brain barrier (BBB) compromise and peripheral immune components infiltration have also been reported in PD patients [12,13]. These infiltrated immune components may interact with DA neurons and lead to DA neuronal demise directly. More recently, miRNAs have been revealed to be regulated by the PD risk genes and may contribute to PD through a direct regulation on the mitochondrial and immune pathways.

\section{Search Strategy/Methods}

Using the advanced search builder function in PubMed, a systemic search was performed with keywords "'MicroRNAs" (Majr) and Parkinson's disease' in September 2019. This resulted in 253 titles consisting of both reviews and original research articles. All relevant articles including screening studies and mechanistic studies were examined to identify the promising microRNAs in PD that are discussed in this review.

\section{The Biogenesis and Function of miRNAs}

MicroRNAs are small non-coding RNAs that are transcribed from miRNA genes and intronic sequences as primary miRNAs (pri-miRNAs) and stem-loop precursor miRNAs (pre-miRNAs) respectively. In the nucleus, pri-miRNAs are further processed to form pre-miRNAs by the Drosha/DGCR8 complex. Pre-miRNAs are then exported out of the nucleus by Exportin-5. In the cytosol, pre-miRNAs are cleaved by Dicer to produce double-stranded mature miRNAs. The mature guide strand, about 20-22 nucleotides long, is then loaded onto Argonaute proteins to form the RNA-induced silencing complex (RISC). The mature miRNA is responsible for associating RISC to its target messenger RNAs (mRNAs) by binding at complementary sequences located usually at the $3^{\prime}$-UTR of the mRNA [14,15] and function as powerful regulators of gene expression. The specificity of the targeting is especially dependent on the seed sequence of the miRNA found at the $5^{\prime}$-end (bases $2-8)$ of the miRNA $[16,17]$. When miRNAs originate from the same predicted precursor, they are assigned names in the form of miR-1-5p (from the $5^{\prime}$-arm) and miR-1-3p (from the $3^{\prime}$-arm). If the relative abundance is known, they can also be named as miR-1 (predominantly-expressed product) and miR-1* (from the opposite arm of the precursor). Identical mature miRNAs that are expressed from different precursor sequences and genomic loci are assigned names in the form of miR-1-1 and miR-1-2. Closely related mature sequences are assigned lettered suffixes, for example, miR-1a and miR-1b would be expressed from precursors mir-1a and mir-1b, respectively [18]. The binding of miRNA to its targets results in translational repression and downregulation in target protein expression.

Since the discovery of miRNAs in 1993, increasing evidence have revealed miRNAs to be important biological molecules involved in diverse processes to maintain normal cellular functions [19-21]. In addition, extracellular miRNAs are relatively stable as they are protected from degradation by being bound to RNA-binding proteins and/or being packaged into exosomes [22], thus, revealing its potential 
as diagnostic biomarkers in diseases. The dysregulation of miRNAs may contribute to the development of various diseases from brain disorders to cancers $[23,24]$. In fact, many studies have shown that the miRNAs expression profile is dysregulated in PD and may contribute to PD pathogenesis. Figure 1 shows some of the key dysfunctional processes in PD that could be regulated by PD-specific miRNAs.

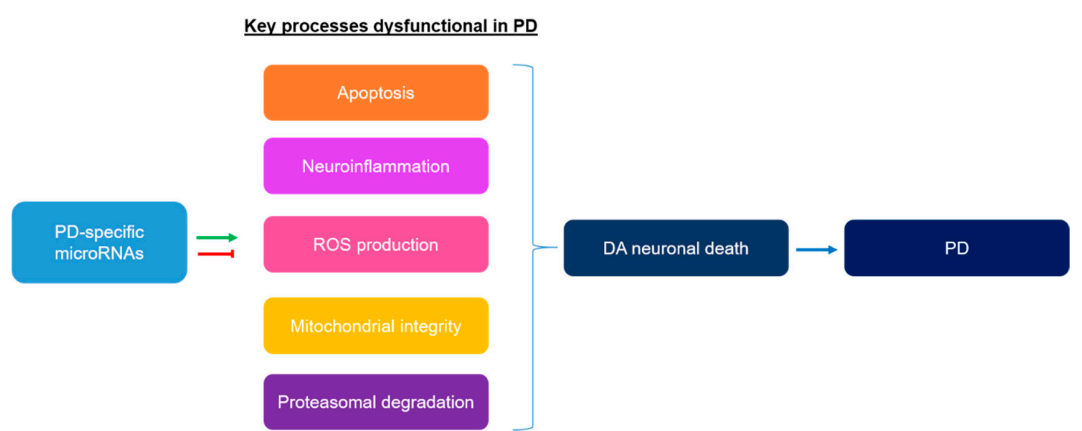

Figure 1. Key processes that are dysfunctional in Parkinson's disease (PD) and could be regulated by a group of PD-specific differentially expressed miRNAs.

Using techniques such as RNA sequencing, microarray and microRNA qPCR profiling, many screening studies have been conducted in attempt to characterise the miRNAs dysregulation in PD in both the central nervous system (CNS) and the periphery. Our search strategy revealed 34 screening studies that have been conducted to identify the clinically significant miRNAs in PD. We included studies on animal PD models and in vitro neuronal models as we believe that clinically significant miRNAs identified in PD patients will also be highlighted in these models. Moreover, due to the difficulty in obtaining human PD patients' samples, the inclusion of these model studies can also reveal suitable PD models to study mechanisms of the identified miRNA(s). In Table 1, we show the list of miRNAs that have been identified by more than 3 screening studies to be dysregulated in PD. Of the miRNAs listed in Table 1,15 miRNAs have been reported to be dysregulated in all three areas; the brain/neuronal model(s), cerebrospinal fluid (CSF) and blood. In Table 2, we show the details of the studies on these 15 miRNAs, including the methods used, the PD models employed and the area(s) studied.

Table 1. Summary of dysregulated miRNAs in PD identified by more than 3 screening studies.

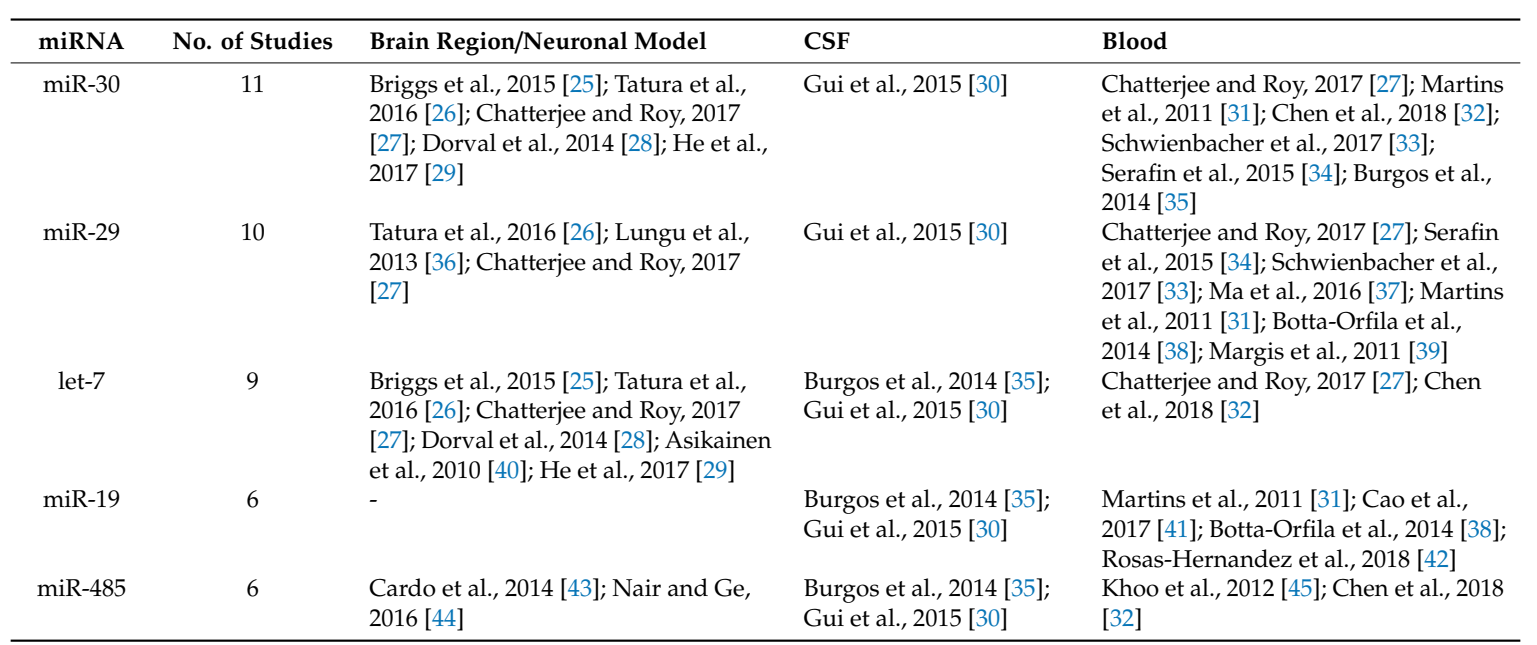


Table 1. Cont.

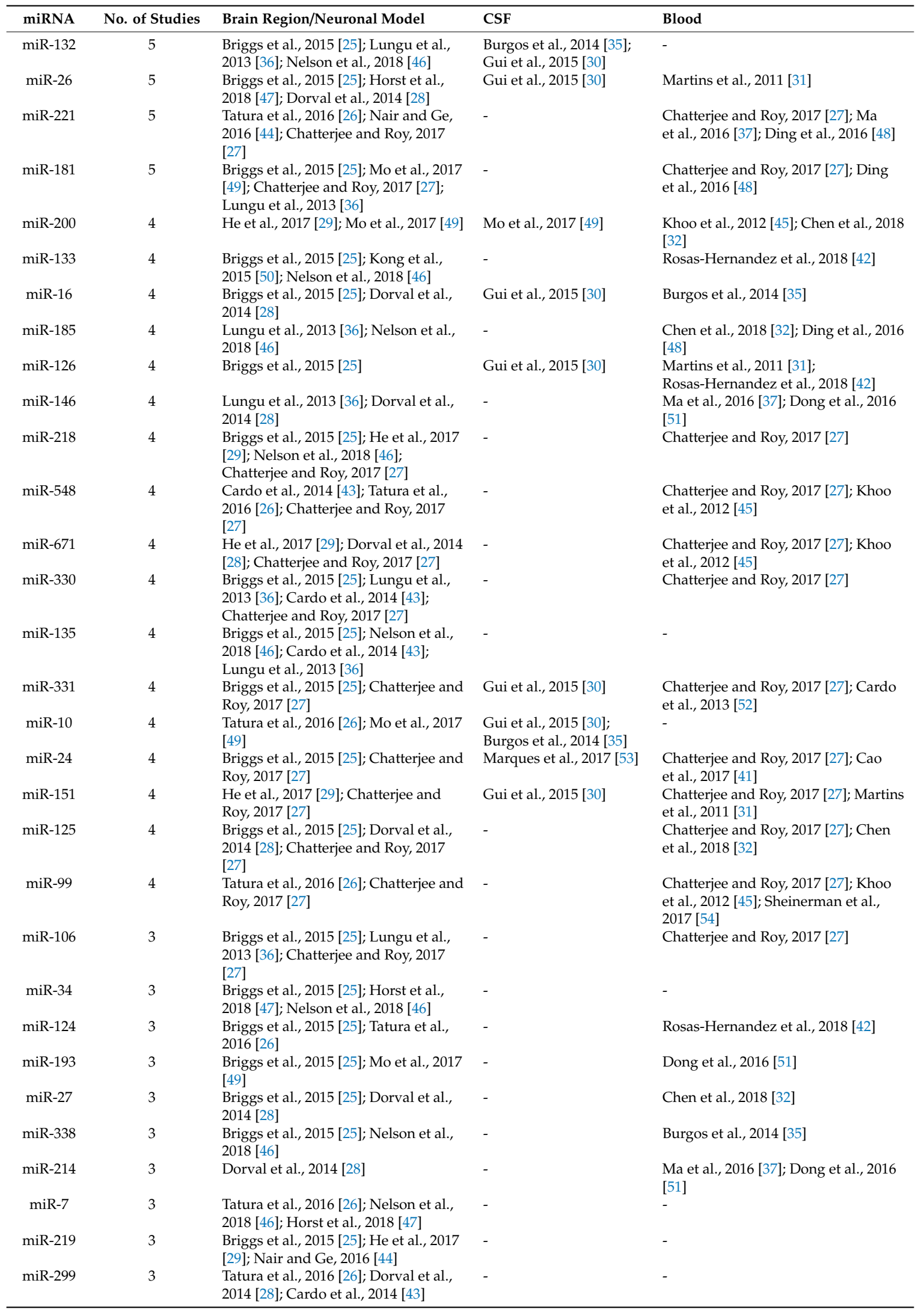


Table 1. Cont.

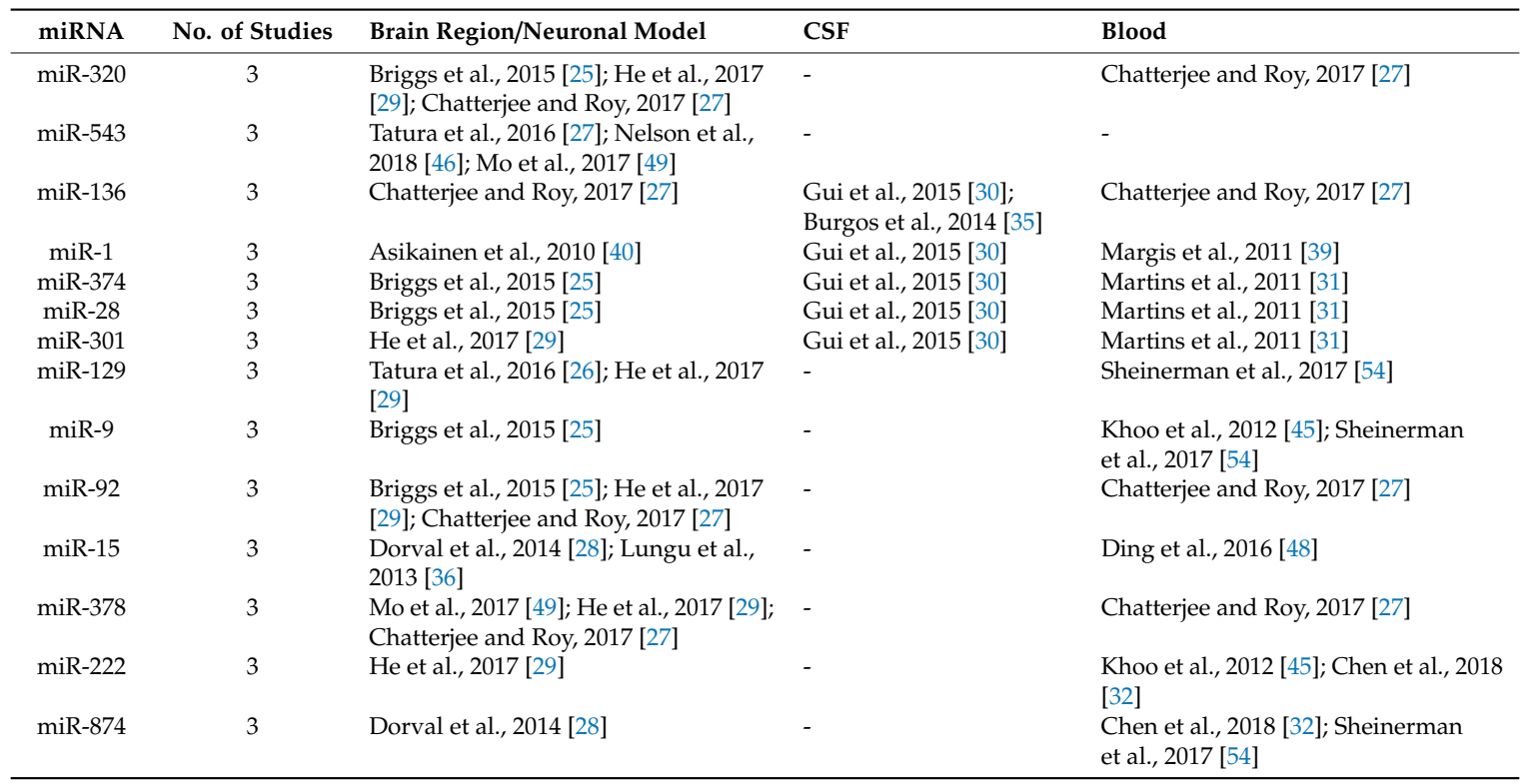


Table 2. Summary of 15 miRNAs reported to be dysregulated in the brain/neuronal model(s), cerebrospinal fluid (CSF) and blood.

\begin{tabular}{|c|c|c|c|c|c|c|c|}
\hline miRNA Family & miRNA Member & Trend & Brain Region/Neuronal Model & CSF & Blood & Method & Ref. \\
\hline \multirow[t]{12}{*}{ miR-30 } & hsa-miR-30b & $\uparrow$ & $\begin{array}{l}\text { SN tissues from } 8 \text { controls vs } 8 \\
\text { PD patients ( } 5 \text { males and } 3 \\
\text { females in each group) }\end{array}$ & - & - & $\begin{array}{l}\text { Human MicroRNA TaqMan } \\
\text { Arrays A } 2.0\end{array}$ & [25] \\
\hline & $\begin{array}{l}\text { hsa-miR-30c-2, } \\
\text {-30d }\end{array}$ & $\uparrow$ & $\begin{array}{l}\text { Anterior cingulate gyri from } 10 \\
\text { controls vs. } 22 \text { PD patients }\end{array}$ & - & - & $\begin{array}{l}\text { TaqMan Array MicroRNA cards } \\
\text { (pools A and B) }\end{array}$ & [26] \\
\hline & hsa-miR-30c-2 & $-\#$ & $\begin{array}{l}\text { Prefrontal cortex from } 33 \text { controls } \\
\text { vs. } 29 \text { PD patients }\end{array}$ & - & $\begin{array}{l}\text { Leukocytes from } 6 \\
\text { controls vs. } 7 \text { PD } \\
\text { patients (All males) }\end{array}$ & $\begin{array}{l}\text { Comparative analysis of } \\
\text { GSE72962 (non-coding RNA } \\
\text { sequencing) and GSE40915 } \\
\text { (non-coding RNA sequencing) }\end{array}$ & {$[27,55,56]$} \\
\hline & mmu-miR-30a* & $\uparrow$ & $\begin{array}{l}\text { Striatal tissues of } \\
\text { LRRK2-knockout mice vs. } \\
\text { controls (4 per group) }\end{array}$ & - & - & $\begin{array}{l}\text { Mouse Gene } 1.0 \mathrm{ST} \text { and miRNA } \\
\text { (v1 or v2) microarrays } \\
\text { (Affymetrix) }\end{array}$ & [28] \\
\hline & hsa-miR-30c-1-3p & $\downarrow$ & $\mathrm{MnCl}_{2}$-treated SH-SY5Y cells & - & - & $\begin{array}{l}\text { Small RNA sequencing (Illumina } \\
\text { HiSeq2000) }\end{array}$ & [29] \\
\hline & hsa-miR-30b & $\uparrow$ & - & $\begin{array}{l}\text { Exosomes isolated from } \\
\text { CSF from } 27 \text { controls vs. } \\
47 \text { PD patients }\end{array}$ & 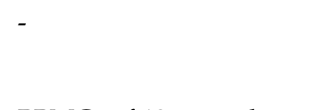 & $\begin{array}{l}\text { TaqMan Low-Density Array } \\
\text { Human miRNA Panels (pool A } \\
\text { and B) }\end{array}$ & {$[30]$} \\
\hline & hsa-miR-30b, -30c & $\downarrow$ & - & - & $\begin{array}{l}\text { PBMCs of } 13 \text { controls } \\
\text { and } 19 \text { PD patients }\end{array}$ & $\begin{array}{l}\text { Exiqon-developed miRCURY } \\
\text { LNA array (version 10.0) }\end{array}$ & {$[31]$} \\
\hline & hsa-miR-30a & $\downarrow$ & - & - & $\begin{array}{l}\text { Plasma from } 25 \text { controls } \\
\text { vs. } 25 \text { drug-naïve PD } \\
\text { patients }\end{array}$ & $\begin{array}{l}\text { A customized neurodegenerative } \\
\text { disease-related } 91 \text { miRNA panel } \\
\text { prepared by miRGenes }\end{array}$ & [32] \\
\hline & hsa-miR-30a-5p & $\uparrow$ & - & - & $\begin{array}{l}\text { Plasma from } 99 \\
\text { L-dopa-treated PD } \\
\text { patients vs. control pairs }\end{array}$ & qPCR & [33] \\
\hline & hsa-miR-30b-5p & $\uparrow$ & - & - & $\begin{array}{l}\text { Plasma from } 10 \\
\text { drug-naive PD patients } \\
\text { vs. control pairs }\end{array}$ & qPCR & [33] \\
\hline & hsa-miR-30b-5p & $\uparrow$ & - & - & $\begin{array}{l}\text { WBCs from } 36 \\
\text { L-dopa-treated PD } \\
\text { patients vs. control pairs }\end{array}$ & qPCR & {$[33,34]$} \\
\hline & $\begin{array}{l}\text { hsa-miR-30a-3p, } \\
-30 \text { e-3p }\end{array}$ & $\uparrow$ & - & - & $\begin{array}{l}\text { Serum from } 60 \mathrm{PD} \\
\text { patients vs. } 72 \text { controls }\end{array}$ & $\begin{array}{l}\text { Illumina TruSeq Small RNA } \\
\text { sequencing (Illumina HiSeq2000) }\end{array}$ & [35] \\
\hline
\end{tabular}


Table 2. Cont.

\begin{tabular}{|c|c|c|c|c|c|c|c|}
\hline miRNA Family & miRNA Member & Trend & Brain Region/Neuronal Model & CSF & Blood & Method & Ref. \\
\hline \multirow[t]{9}{*}{ miR-29 } & $\begin{array}{l}\text { hsa-miR-29a, } \\
-29 b-1,-29 b-2\end{array}$ & $\uparrow$ & $\begin{array}{l}\text { Anterior cingulate gyri from } 10 \\
\text { controls vs. } 22 \text { PD patients }\end{array}$ & - & - & $\begin{array}{l}\text { TaqMan Array MicroRNA cards } \\
\text { (pools A and B) }\end{array}$ & [26] \\
\hline & $\begin{array}{l}\text { rno-miR-29a-3p, } \\
-29 b-2-5 p\end{array}$ & $\uparrow$ & $\begin{array}{l}\text { Mesencephalon brain areas from } \\
\text { BD-IV affected rats }(n=3) \text { vs. } \\
\text { control BD-IV rats }(n=3)\end{array}$ & - & - & $\begin{array}{l}\text { Microarray (Chip ID miRRat } 19.0 \\
\text { version) }\end{array}$ & [36] \\
\hline & hsa-miR-29b-2-5p & $-\#$ & $\begin{array}{l}\text { Prefrontal cortex from } 33 \text { controls } \\
\text { vs. } 29 \text { PD patients }\end{array}$ & - & $\begin{array}{l}\text { Leukocytes from } 6 \\
\text { controls vs. } 7 \text { PD } \\
\text { patients (All males) }\end{array}$ & $\begin{array}{l}\text { Comparative analysis of } \\
\text { GSE72962 (non-coding RNA } \\
\text { sequencing) and GSE40915 } \\
\text { (non-coding RNA sequencing) }\end{array}$ & {$[27,55,56]$} \\
\hline & hsa-miR-29c & $\downarrow$ & - & $\begin{array}{l}\text { Exosomes isolated from } \\
\text { CSF from } 27 \text { controls vs. } \\
47 \text { PD patients }\end{array}$ & - & $\begin{array}{l}\text { TaqMan Low-Density Array } \\
\text { Human miRNA Panels (pool A } \\
\text { and B) }\end{array}$ & [30] \\
\hline & hsa-miR-29a-3p & $\uparrow$ & - & - & $\begin{array}{l}\text { WBCs from } 36 \\
\text { L-dopa-treated PD } \\
\text { patients vs. control pairs }\end{array}$ & qPCR & {$[33,34]$} \\
\hline & hsa-miR-29c & $\downarrow$ & - & - & $\begin{array}{l}\text { Serum from } 138 \text { PD } \\
\text { patients vs. } 112 \text { controls }\end{array}$ & qPCR & [37] \\
\hline & hsa-miR-29b, -29c & $\downarrow$ & - & - & $\begin{array}{l}\text { PBMCs of } 13 \text { controls } \\
\text { and } 19 \text { PD patients }\end{array}$ & $\begin{array}{l}\text { Exiqon-developed miRCURY } \\
\text { LNA array (version 10.0) }\end{array}$ & [31] \\
\hline & hsa-miR-29a, -29c & $\downarrow$ & - & - & $\begin{array}{l}\text { Serum from } 65 \\
\text { idopathic PD patients vs. } \\
65 \text { controls }\end{array}$ & $\begin{array}{l}\text { TaqMan Array MicroRNA A } \\
\text { Cards v2.0 followed by qPCR }\end{array}$ & [38] \\
\hline & hsa-miR-29a & $\downarrow$ & - & - & $\begin{array}{l}\text { Blood from } 8 \text { untreated } \\
\text { PD patients, } 4 \\
\text { drug-treated PD } \\
\text { patients vs. } 8 \text { controls }\end{array}$ & qPCR & [39] \\
\hline
\end{tabular}


Table 2. Cont.

\begin{tabular}{|c|c|c|c|c|c|c|c|}
\hline miRNA Family & miRNA Member & Trend & Brain Region/Neuronal Model & CSF & Blood & Method & Ref. \\
\hline \multirow[t]{9}{*}{ let-7 } & hsa-let-7b & $\uparrow$ & $\begin{array}{l}\text { SN tissues from } 8 \text { controls vs. } 8 \\
\text { PD patients ( } 5 \text { males and } 3 \\
\text { females in each group) }\end{array}$ & - & - & $\begin{array}{l}\text { Human MicroRNA TaqMan } \\
\text { Arrays A } 2.0\end{array}$ & [25] \\
\hline & hsa-let-7e & $\uparrow$ & $\begin{array}{l}\text { Anterior cingulate gyri from } 10 \\
\text { controls vs. } 22 \text { PD patients }\end{array}$ & - & - & $\begin{array}{l}\text { TaqMan Array MicroRNA cards } \\
\text { (pools A and B) }\end{array}$ & [26] \\
\hline & $\begin{array}{l}\text { hsa-let-7d-5p, } \\
-7 f-5 p,-7 g\end{array}$ & $-\#$ & $\begin{array}{l}\text { Prefrontal cortex from } 33 \text { controls } \\
\text { vs. } 29 \text { PD patients }\end{array}$ & - & $\begin{array}{l}\text { Leukocytes from } 6 \\
\text { controls vs. } 7 \text { PD } \\
\text { patients (All males) }\end{array}$ & $\begin{array}{l}\text { Comparative analysis of } \\
\text { GSE72962 (non-coding RNA } \\
\text { sequencing) and GSE40915 } \\
\text { (non-coding RNA sequencing) }\end{array}$ & {$[27,55,56]$} \\
\hline & mmu-let-7f & $\uparrow$ & $\begin{array}{l}\text { Striatal tissues of } \\
\text { LRRK2-knockout mice vs. } \\
\text { controls (4 per group) }\end{array}$ & - & - & $\begin{array}{l}\text { Mouse Gene } 1.0 \text { ST and miRNA } \\
\text { (v1 or v2) microarrays } \\
\text { (Affymetrix) }\end{array}$ & [28] \\
\hline & cel-let-7 & $\downarrow$ & $\begin{array}{l}\text { A53T } \alpha \text {-synuclein transgenic } C \text {. } \\
\text { elegans vs. wildtype }\end{array}$ & - & - & $\begin{array}{l}\text { Ncode Multispecies miRNA } \\
\text { Microarray V2-arrays }\end{array}$ & [40] \\
\hline & hsa-let-7f-1-3p & $\downarrow$ & $\mathrm{MnCl}_{2}$-treated SH-SY5Y cells & 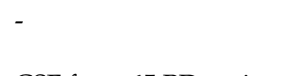 & - & $\begin{array}{l}\text { Small RNA sequencing (Illumina } \\
\text { HiSeq2000) }\end{array}$ & [29] \\
\hline & hsa-let-7g-3p & $\uparrow$ & - & $\begin{array}{l}\text { CSF from } 65 \text { PD patients } \\
\text { vs. } 70 \text { controls }\end{array}$ & - & $\begin{array}{l}\text { Illumina TruSeq Small RNA } \\
\text { sequencing (Illumina HiSeq2000) }\end{array}$ & [35] \\
\hline & hsa-let-7g-3p & $\uparrow$ & - & $\begin{array}{l}\text { Exosomes isolated from } \\
\text { CSF from } 27 \text { controls vs. } \\
47 \text { PD patients }\end{array}$ & - & $\begin{array}{l}\text { TaqMan Low-Density Array } \\
\text { Human miRNA Panels (pool A } \\
\text { and B) }\end{array}$ & {$[30]$} \\
\hline & hsa-let-7a, -7f & $\downarrow$ & - & - & $\begin{array}{l}\text { Plasma from } 25 \text { controls } \\
\text { vs. } 25 \text { drug-naïve PD } \\
\text { patients }\end{array}$ & $\begin{array}{l}\text { A customized neurodegenerative } \\
\text { disease-related } 91 \text { miRNA panel } \\
\text { prepared by miRGenes }\end{array}$ & [32] \\
\hline \multirow[t]{6}{*}{$\operatorname{miR}-485$} & hsa-miR-485-5p & $\downarrow$ & $\begin{array}{l}\text { SN tissues from } 4 \text { controls vs. } 8 \\
\text { PD patients }\end{array}$ & - & - & TaqMan low-density array & [43] \\
\hline & hsa-miR-485-3p & $\uparrow$ & $\begin{array}{l}\text { Putamen tissues from } 12 \text { PD } \\
\text { patients vs. } 12 \text { controls }\end{array}$ & - & - & $\begin{array}{l}\text { nCounter Human v2 miRNA } \\
\text { Expression Assay kit }\end{array}$ & [44] \\
\hline & hsa-miR-485-5p & $\uparrow$ & - & $\begin{array}{l}\text { Exosomes isolated from } \\
\text { CSF from } 27 \text { controls vs. } \\
47 \text { PD patients }\end{array}$ & - & $\begin{array}{l}\text { TaqMan Low-Density Array } \\
\text { Human miRNA Panels (pool A } \\
\text { and B) }\end{array}$ & {$[30]$} \\
\hline & hsa-miR-485-5p & $\downarrow$ & - & $\begin{array}{l}\text { CSF from } 65 \text { PD patients } \\
\text { vs. } 70 \text { controls }\end{array}$ & - & $\begin{array}{l}\text { Illumina TruSeq Small RNA } \\
\text { sequencing (Illumina HiSeq2000) }\end{array}$ & [35] \\
\hline & hsa-miR-485-5p & $\downarrow$ & - & - & $\begin{array}{l}\text { Plasma from } 32 \mathrm{PD} \\
\text { patients vs. } 32 \text { controls }\end{array}$ & $\begin{array}{l}\text { Agilent whole human genome } \\
\text { miRNA microarray v.3 }\end{array}$ & [45] \\
\hline & hsa-miR-485-5p & $\downarrow$ & - & - & $\begin{array}{l}\text { Plasma from } 25 \text { controls } \\
\text { vs. } 25 \text { drug-naïve PD } \\
\text { patients }\end{array}$ & $\begin{array}{l}\text { A customized neurodegenerative } \\
\text { disease-related } 91 \text { miRNA panel } \\
\text { prepared by miRGenes }\end{array}$ & [32] \\
\hline
\end{tabular}


Table 2. Cont

\begin{tabular}{|c|c|c|c|c|c|c|c|}
\hline miRNA Family & miRNA Member & Trend & Brain Region/Neuronal Model & CSF & Blood & Method & Ref. \\
\hline \multirow[t]{5}{*}{ miR-26 } & hsa-miR-26a-5p & $\uparrow$ & $\begin{array}{l}\text { SN tissues from } 8 \text { controls vs. } 8 \\
\text { PD patients ( } 5 \text { males and } 3 \\
\text { females in each group) }\end{array}$ & - & - & $\begin{array}{l}\text { Human MicroRNA TaqMan } \\
\text { Arrays A } 2.0\end{array}$ & [25] \\
\hline & rno-miR-26a & $\uparrow$ & $\begin{array}{l}\text { Striatal tissues from } \\
\text { rotenone-induced Wistar rats vs. } \\
\text { control }\end{array}$ & - & - & qPCR & [47] \\
\hline & mmu-miR-26b & $\uparrow$ & $\begin{array}{l}\text { Striatal tissues of } \\
\text { LRRK2-knockout mice vs. } \\
\text { controls ( } 4 \text { per group) }\end{array}$ & - & - & $\begin{array}{l}\text { Mouse Gene } 1.0 \text { ST and miRNA } \\
\text { (v1 or v2) microarrays } \\
\text { (Affymetrix) }\end{array}$ & [28] \\
\hline & hsa-miR-26a & $\uparrow$ & - & $\begin{array}{l}\text { Exosomes isolated from } \\
\text { CSF from } 27 \text { controls vs. } \\
47 \text { PD patients }\end{array}$ & - & $\begin{array}{l}\text { TaqMan Low-Density Array } \\
\text { Human miRNA Panels (pool A } \\
\text { and B) }\end{array}$ & [30] \\
\hline & hsa-miR-26a & $\downarrow$ & - & - & $\begin{array}{l}\text { PBMCs of } 13 \text { controls } \\
\text { and } 19 \text { PD patients }\end{array}$ & $\begin{array}{l}\text { Exiqon-developed miRCURY } \\
\text { LNA array (version 10.0) }\end{array}$ & [31] \\
\hline \multirow[t]{5}{*}{$\mathrm{miR}-200$} & hsa-miR-200a-5p & $\uparrow$ & $\mathrm{MnCl}_{2}$-treated SH-SY5Y cells & - & - & $\begin{array}{l}\text { Small RNA sequencing (Illumina } \\
\text { HiSeq2000) }\end{array}$ & [29] \\
\hline & $\begin{array}{l}\text { mmu-miR-200b-3p, } \\
-200 a-3 p,-200 c-3 p \\
200 a-5 p\end{array}$ & $\uparrow$ & $\begin{array}{l}\text { Midbrain tissues of A53T } \alpha \\
\text {-synuclein-transgenic mice vs. } \\
\text { wildtype }\end{array}$ & - & - & $\begin{array}{l}\text { Illumina TruSeq Small RNA } \\
\text { sequencing (Illumina HiSeq2500) }\end{array}$ & [49] \\
\hline & hsa-miR-200a-3p & $\uparrow$ & - & $\begin{array}{l}\text { CSF from } 44 \text { PD patients } \\
\text { vs. } 42 \text { controls }\end{array}$ & - & qPCR & [49] \\
\hline & hsa-miR-200a & $\uparrow$ & - & - & $\begin{array}{l}\text { Plasma from } 32 \mathrm{PD} \\
\text { patients vs. } 32 \text { controls }\end{array}$ & $\begin{array}{l}\text { Agilent whole human genome } \\
\text { miRNA microarray v. } 3\end{array}$ & [45] \\
\hline & hsa-miR-200a & $\downarrow$ & - & - & $\begin{array}{l}\text { Plasma from } 25 \text { controls } \\
\text { vs. } 25 \text { drug-naïve PD } \\
\text { patients }\end{array}$ & $\begin{array}{l}\text { A customized neurodegenerative } \\
\text { disease-related } 91 \text { miRNA panel } \\
\text { prepared by miRGenes }\end{array}$ & [32] \\
\hline \multirow[t]{4}{*}{ miR-16 } & hsa-miR-16 & $\uparrow$ & $\begin{array}{l}\text { SN tissues from } 8 \text { controls vs. } 8 \\
\text { PD patients ( } 5 \text { males and } 3 \\
\text { females in each group) }\end{array}$ & - & - & $\begin{array}{l}\text { Human MicroRNA TaqMan } \\
\text { Arrays A } 2.0\end{array}$ & [25] \\
\hline & mmu-miR-16 & $\uparrow$ & $\begin{array}{l}\text { Striatal tissues of } \\
\text { LRRK2-knockout mice vs. } \\
\text { controls (4 per group) }\end{array}$ & - & - & $\begin{array}{l}\text { Mouse Gene } 1.0 \mathrm{ST} \text { and miRNA } \\
\text { (v1 or v2) microarrays } \\
\text { (Affymetrix) followed by qPCR } \\
\text { validation }\end{array}$ & [28] \\
\hline & hsa-miR-16-2 & $\uparrow$ & - & $\begin{array}{l}\text { Exosomes isolated from } \\
\text { CSF from } 27 \text { controls vs. } \\
47 \text { PD patients }\end{array}$ & - & $\begin{array}{l}\text { TaqMan Low-Density Array } \\
\text { Human miRNA Panels (pool A } \\
\text { and B) }\end{array}$ & [30] \\
\hline & hsa-miR-16-2-3p & $\downarrow$ & - & - & $\begin{array}{l}\text { Serum from } 60 \mathrm{PD} \\
\text { patients vs. } 72 \text { controls }\end{array}$ & $\begin{array}{l}\text { Illumina TruSeq Small RNA } \\
\text { sequencing (Illumina HiSeq2000) }\end{array}$ & [35] \\
\hline
\end{tabular}


Table 2. Cont

\begin{tabular}{|c|c|c|c|c|c|c|c|}
\hline miRNA Family & miRNA Member & Trend & Brain Region/Neuronal Model & CSF & Blood & Method & Ref. \\
\hline \multirow[t]{4}{*}{ miR-126 } & hsa-miR-126 & $\uparrow$ & $\begin{array}{l}\text { SN tissues from } 8 \text { controls vs. } 8 \\
\text { PD patients ( } 5 \text { males and } 3 \\
\text { females in each group) }\end{array}$ & - & - & $\begin{array}{l}\text { Human MicroRNA TaqMan } \\
\text { Arrays A } 2.0\end{array}$ & [25] \\
\hline & hsa-miR-126 & $\downarrow$ & - & $\begin{array}{l}\text { Exosomes isolated from } \\
\text { CSF from } 27 \text { controls vs. } \\
47 \text { PD patients }\end{array}$ & - & $\begin{array}{l}\text { TaqMan Low-Density Array } \\
\text { Human miRNA Panels (pool A } \\
\text { and B) }\end{array}$ & {$[30]$} \\
\hline & hsa-miR-126*, -126 & $\downarrow$ & - & - & $\begin{array}{l}\text { PBMCs of } 13 \text { controls } \\
\text { and } 19 \text { PD patients }\end{array}$ & $\begin{array}{l}\text { Exiqon-developed miRCURY } \\
\text { LNA array (version 10.0) }\end{array}$ & [31] \\
\hline & mmu-miR-126a & $\downarrow$ & - & - & $\begin{array}{l}\text { Serum from } \\
\text { MPTP-treated mice vs. } \\
\text { control }\end{array}$ & Next generation sequencing & [42] \\
\hline \multirow[t]{4}{*}{ miR-331 } & hsa-miR-331-3p & $\uparrow$ & $\begin{array}{l}\text { SN tissues from } 8 \text { controls vs. } 8 \\
\text { PD patients ( } 5 \text { males and } 3 \\
\text { females in each group) }\end{array}$ & - & - & $\begin{array}{l}\text { Human MicroRNA TaqMan } \\
\text { Arrays A } 2.0\end{array}$ & [25] \\
\hline & hsa-miR-331 & $-\#$ & $\begin{array}{l}\text { Prefrontal cortex from } 33 \text { controls } \\
\text { vs. } 29 \text { PD patients }\end{array}$ & - & $\begin{array}{l}\text { Leukocytes from } 6 \\
\text { controls vs. } 7 \text { PD } \\
\text { patients (All males) }\end{array}$ & $\begin{array}{l}\text { Comparative analysis of } \\
\text { GSE72962 (non-coding RNA } \\
\text { sequencing) and GSE40915 } \\
\text { (non-coding RNA sequencing) }\end{array}$ & {$[27,55,56]$} \\
\hline & hsa-miR-331-5p & $\uparrow$ & - & $\begin{array}{l}\text { Exosomes isolated from } \\
\text { CSF from } 27 \text { controls vs. } \\
47 \text { PD patients }\end{array}$ & - & $\begin{array}{l}\text { TaqMan Low-Density Array } \\
\text { Human miRNA Panels (pool A } \\
\text { and B) }\end{array}$ & {$[30]$} \\
\hline & hsa-miR-331-5p & $\uparrow$ & - & - & $\begin{array}{l}\text { Plasma from } 25 \text { controls } \\
\text { vs. } 31 \text { PD patients }\end{array}$ & $\begin{array}{l}\text { TaqMan low density miRNA } \\
\text { cards followed by qPCR } \\
\text { validation }\end{array}$ & [52] \\
\hline \multirow[t]{4}{*}{$\operatorname{miR}-24$} & hsa-miR-24 & $\uparrow$ & $\begin{array}{l}\text { SN tissues from } 8 \text { controls vs. } 8 \\
\text { PD patients ( } 5 \text { males and } 3 \\
\text { females in each group) }\end{array}$ & - & - & $\begin{array}{l}\text { Human MicroRNA TaqMan } \\
\text { Arrays A } 2.0\end{array}$ & [25] \\
\hline & hsa-miR-24-3p & $-\#$ & $\begin{array}{l}\text { Prefrontal cortex from } 33 \text { controls } \\
\text { vs. } 29 \text { PD patients }\end{array}$ & - & $\begin{array}{l}\text { Leukocytes from } 6 \\
\text { controls vs. } 7 \text { PD } \\
\text { patients (All males) }\end{array}$ & $\begin{array}{l}\text { Comparative analysis of } \\
\text { GSE72962 (non-coding RNA } \\
\text { sequencing) and GSE40915 } \\
\text { (non-coding RNA sequencing) }\end{array}$ & {$[27,55,56]$} \\
\hline & hsa-miR-24 & $\downarrow$ & - & $\begin{array}{l}\text { CSF from } 28 \text { PD patients } \\
\text { vs. } 28 \text { controls }\end{array}$ & - & qPCR & [53] \\
\hline & hsa-miR-24 & $\uparrow$ & - & - & $\begin{array}{l}\text { Exosomes isolated from } \\
\text { serum of } 109 \text { PD } \\
\text { patients vs. } 40 \text { controls }\end{array}$ & qPCR & [41] \\
\hline
\end{tabular}


Table 2. Cont.

\begin{tabular}{|c|c|c|c|c|c|c|c|}
\hline miRNA Family & miRNA Member & Trend & Brain Region/Neuronal Model & CSF & Blood & Method & Ref. \\
\hline \multirow[t]{4}{*}{ miR-151 } & hsa-miR-151b & $\downarrow$ & $\mathrm{MnCl}_{2}$-treated SH-SY5Y cells & - & - & $\begin{array}{l}\text { Small RNA sequencing (Illumina } \\
\text { HiSeq2000) }\end{array}$ & [29] \\
\hline & $\begin{array}{l}\text { hsa-miR-151a-5p, } \\
\text {-151b }\end{array}$ & $-\#$ & $\begin{array}{l}\text { Prefrontal cortex from } 33 \text { controls } \\
\text { vs. } 29 \text { PD patients }\end{array}$ & - & $\begin{array}{l}\text { Leukocytes from } 6 \\
\text { controls vs. } 7 \text { PD } \\
\text { patients (All males) }\end{array}$ & $\begin{array}{l}\text { Comparative analysis of } \\
\text { GSE72962 (non-coding RNA } \\
\text { sequencing) and GSE40915 } \\
\text { (non-coding RNA sequencing) }\end{array}$ & {$[27,55,56]$} \\
\hline & hsa-miR-151 & $\downarrow$ & - & $\begin{array}{l}\text { Exosomes isolated from } \\
\text { CSF from } 27 \text { controls vs. } \\
47 \text { PD patients }\end{array}$ & - & $\begin{array}{l}\text { TaqMan Low-Density Array } \\
\text { Human miRNA Panels (pool A } \\
\text { and B) }\end{array}$ & {$[30]$} \\
\hline & $\begin{array}{l}\text { hsa-miR-151-5p, } \\
-151-3 p\end{array}$ & $\downarrow$ & - & - & $\begin{array}{l}\text { PBMCs of } 13 \text { controls } \\
\text { and } 19 \text { PD patients }\end{array}$ & $\begin{array}{l}\text { Exiqon-developed miRCURY } \\
\text { LNA array (version 10.0) }\end{array}$ & [31] \\
\hline \multirow[t]{3}{*}{ miR-1 } & cel-miR-1 & $\downarrow$ & $\begin{array}{l}\text { A53T } \alpha \text {-synuclein transgenic } C \text {. } \\
\text { elegans vs. wildtype }\end{array}$ & - & - & $\begin{array}{l}\text { Ncode Multispecies miRNA } \\
\text { Microarray V2-arrays }\end{array}$ & [40] \\
\hline & hsa-miR-1 & $\downarrow$ & - & $\begin{array}{l}\text { Exosomes isolated from } \\
\text { CSF from } 27 \text { controls vs. } \\
47 \text { PD patients }\end{array}$ & - & $\begin{array}{l}\text { TaqMan Low-Density Array } \\
\text { Human miRNA Panels (pool A } \\
\text { and B) }\end{array}$ & {$[30]$} \\
\hline & hsa-miR-1 & $\downarrow$ & - & - & $\begin{array}{l}\text { Blood from } 8 \text { untreated } \\
\text { PD patients vs. } 8 \\
\text { controls }\end{array}$ & qPCR & [39] \\
\hline \multirow[t]{3}{*}{$\operatorname{miR}-374$} & hsa-miR-374a & $\uparrow$ & $\begin{array}{l}\text { SN tissues from } 8 \text { controls vs. } 8 \\
\text { PD patients ( } 5 \text { males and } 3 \\
\text { females in each group) }\end{array}$ & - & - & $\begin{array}{l}\text { Human MicroRNA TaqMan } \\
\text { Arrays A } 2.0\end{array}$ & [25] \\
\hline & hsa-miR-374 & $\downarrow$ & - & $\begin{array}{l}\text { Exosomes isolated from } \\
\text { CSF from } 27 \text { controls vs. } \\
47 \text { PD patients }\end{array}$ & - & $\begin{array}{l}\text { TaqMan Low-Density Array } \\
\text { Human miRNA Panels (pool A } \\
\text { and B) }\end{array}$ & {$[30]$} \\
\hline & $\begin{array}{l}\text { hsa-miR-374a, } \\
\text {-374b }\end{array}$ & $\downarrow$ & - & - & $\begin{array}{l}\text { PBMCs of } 13 \text { controls } \\
\text { and } 19 \text { PD patients }\end{array}$ & $\begin{array}{l}\text { Exiqon-developed miRCURY } \\
\text { LNA array (version 10.0) }\end{array}$ & [31] \\
\hline
\end{tabular}


Table 2. Cont.

\begin{tabular}{|c|c|c|c|c|c|c|c|}
\hline miRNA Family & miRNA Member & Trend & Brain Region/Neuronal Model & CSF & Blood & Method & Ref. \\
\hline \multirow[t]{3}{*}{ miR-28 } & hsa-miR-28-5p & $\uparrow$ & $\begin{array}{l}\text { SN tissues from } 8 \text { controls vs. } 8 \\
\text { PD patients ( } 5 \text { males and } 3 \\
\text { females in each group) }\end{array}$ & - & - & $\begin{array}{l}\text { Human MicroRNA TaqMan } \\
\text { Arrays A } 2.0\end{array}$ & [25] \\
\hline & hsa-miR-28 & $\downarrow$ & - & $\begin{array}{l}\text { Exosomes isolated from } \\
\text { CSF from } 27 \text { controls vs. } \\
47 \text { PD patients }\end{array}$ & - & $\begin{array}{l}\text { TaqMan Low-Density Array } \\
\text { Human miRNA Panels (pool A } \\
\text { and B) }\end{array}$ & [30] \\
\hline & hsa-miR-28-5p & $\downarrow$ & - & - & $\begin{array}{l}\text { PBMCs of } 13 \text { controls } \\
\text { and } 19 \text { PD patients }\end{array}$ & $\begin{array}{l}\text { Exiqon-developed miRCURY } \\
\text { LNA array (version 10.0) }\end{array}$ & [31] \\
\hline \multirow[t]{3}{*}{ miR-301 } & hsa-miR-301a-5p & $\downarrow$ & $\mathrm{MnCl}_{2}$-treated SH-SY5Y cells & - & - & $\begin{array}{l}\text { Small RNA sequencing (Illumina } \\
\text { HiSeq2000) }\end{array}$ & [29] \\
\hline & hsa-miR-301a & $\downarrow$ & - & $\begin{array}{l}\text { Exosomes isolated from } \\
\text { CSF from } 27 \text { controls vs. } \\
47 \text { PD patients }\end{array}$ & - & $\begin{array}{l}\text { TaqMan Low-Density Array } \\
\text { Human miRNA Panels (pool A } \\
\text { and B) }\end{array}$ & [30] \\
\hline & hsa-miR-301a & $\downarrow$ & - & - & $\begin{array}{l}\text { PBMCs of } 13 \text { controls } \\
\text { and } 19 \text { PD patients }\end{array}$ & $\begin{array}{l}\text { Exiqon-developed miRCURY } \\
\text { LNA array (version 10.0) }\end{array}$ & [31] \\
\hline
\end{tabular}

\# A positive correlation of the identified dysregulated miRNA was found in both the prefrontal cortex and the blood leukocytes of PD patients. $\uparrow$ An upregulation in trend observed. $\downarrow$ A downregulation in trend observed. 
The top 5 miRNAs listed in Table 2, namely, miR-30, miR-29, let-7, miR-485 and miR-26 will be reviewed and their possible roles in interaction with PD risk genes, mitochondrial function and immune pathways which may lead to PD progression will be discussed. The significance of miRNA research and the challenges faced in this field will be highlighted.

\section{1. $m i R-30$}

The miR-30 family consists of 5 members and 6 mature miRNA sequences, namely, miR-30a, miR-30b, miR-30c-1, miR-30c-2, miR-30d and miR-30e. The members share a common seed sequence near the $5^{\prime}$-end but has different compensatory sequences near the $3^{\prime}$-end, allowing the different members to target different genes and pathways [57].

In the post-mortem human brain studies, miR-30b in the substantia nigra (SN) [25] and miR-30c-2 and miR-30d in cingulate gyri [26] were found to be upregulated in PD patients compared to healthy controls. Moreover, miR-30b was upregulated in exosomes isolated from the CSF of PD patients [30]. In addition, the dysregulation observed for miR-30c-2 was also found to be positively correlated in both the prefrontal cortex and blood leukocytes of PD patients [27], suggesting the potential of examining the miRNA profile of peripheral leukocytes of PD patients for diagnostic biomarkers.

Besides the CNS, differential expression levels of miR-30 family members have also been detected in the peripheral blood of PD patients as compared to healthy controls. Downregulated expressions of miR-30b and miR-30c in the PBMCs [31] and downregulated miR-30a in the plasma [32] were reported in PD patients. Contrary to these findings, miR-30a-5p and miR-30b-5p were reported to be upregulated in the plasma and WBCs of L-dopa-treated PD patients, respectively, while miR-30b-5p was upregulated in the plasma of drug naïve PD patients [33]. miR-30a-3p and miR-30e-3p were also found to be upregulated in the serum of PD patients [35]. Despite the discrepancies which can be improved through proper stratification of the patients by disease stage and drug treatment during patient recruitment, these discoveries suggest that miR-30 may play functional roles in PD progression.

Using a PD mouse model, Dorval and colleagues (2014) revealed that miR-30a* was upregulated in the striatal tissues of LRRK2-KO mice [28] which indicates that LRRK2 may function through regulating miRNAs expression. In addition, miR-30e has been reported to be neuroprotective in PD. Using the MPTP-induced PD mouse model, Li et al. (2018) found that the delivery of miR-30e agomir improves the mice's motor behavioural performances on the rota-rod, pole and traction tests and the beam-crossing task. miR-30e agomir treatment was also able to attenuate TH loss induced by MPTP, decrease a-syn expression and restore brain-derived neurotrophic factor (BDNF) secretion. $\mathrm{Li}$ and colleagues also showed that miR-30e can ameliorate neuroinflammation by reducing inflammatory cytokines TNF- $\alpha$, COX-2 and iNOS, and target Nlrp3 to inhibit the activation of Nlrp3 inflammasome [58]. Besides its role in regulating neuroinflammation, by comparing the expression profiles of PD patients with rapid and slow progression rates obtained from Gene Expression Omnibus GSE80599, Fan and Xiao (2018) identified a total of 225 differentially expressed genes that were significantly enriched in pathways related to fatty acid metabolism and may be regulated by the miR-30 family members [59]. On the other hand, miR-30a-5p has been reported to target and suppress BDNF expression [60]. Since BDNF contributes to the plasticity and repair of DA neurons [61,62] and a lower BDNF level is associated with greater cognitive impairments in PD patients [63], this suggests that miR-30a may play a neurotoxic role in PD.

\section{2. $m i R-29$}

The miR-29 family consists of 3 members and 4 mature miRNA sequences, namely, miR-29a, miR-29b-1, miR-29b-2 and miR-29c. Mature sequences have identical seed sequences at nucleotide positions 2-7, suggesting that the targets for miR-29 members heavily overlap [64].

In the post-mortem human brain, miR-29a, miR-29b-1 and miR-29b-2 were observed to be upregulated in the anterior cingulate gyri of PD patients [26]. The dysregulation observed for miR-29b-2-5p was also found to be positively correlated in both the prefrontal cortex and blood 
leukocytes of PD patients [27]. In contrast, miR-29c was downregulated in the exosomes isolated from the CSF of PD patients [30].

In the periphery, miR-29a-3p was reported to be upregulated in the WBCs of L-dopa-treated PD patients but not in the untreated PD patients [33]. On the contrary, miR-29a [38] and miR-29c [37,38] levels were observed to be decreased in the serum of PD patients. In addition, miR-29b and miR-29c were downregulated in the PBMCs of PD patients [31] while decreased miR-29a was observed in the blood of both drug-treated and untreated PD patients as compared to healthy controls [39]. It was suggested that blood serum levels of miR-29a and miR-29c tended to decrease with PD severity [65].

miR-29 has been shown to regulate various processes that are important in PD development, such as apoptosis [66-68] and neuronal survival [67], cellular senescence [69,70], fine-tuning motor functions [67,71], immune regulation [72-74] and epigenetic modulation [75,76]. Kole et al. (2011) showed that miR-29b contributes to neuronal survival by targeting genes in the pro-apoptotic BH3-only family to inhibit apoptosis [66]. Moreover, Roshan et al. (2014) demonstrated that the inhibition of miR-29 in the mouse brain resulted in massive cell death especially in the hippocampus and cerebellum [67]. These mice also exhibited characteristics of ataxia such as reduced step length, which suggests a role for miR-29 in motor coordination [67]. In addition, miR-29 also modulates immune responses by regulating $\mathrm{T}$ helper 1 (Th1) differentiation and targeting transcription factors T-bet and Eomes, resulting in the repression of IFN- $\gamma$ production [72]. Downregulation of miR-29 levels in the periphery of PD patients [31,37-39] supports the observation of naïve CD4+ T cells from the peripheral blood of PD patients to preferentially differentiate towards Th1 lineage [77]. These studies suggest that the dysregulation of miR-29 may mediate PD progression.

\section{3. let-7}

The let-7 family members consist of let-7a to let-7-k, miR-98 and miR-202. While the let-7 sequence is well-conserved from nematode to human, different species can express different members of let-7. For example, in humans, we do not express let-7h/j/k. Interestingly, all let-7 members share the same seed sequence (nucleotides 2-8) for target recognition [78].

In post-mortem human brain studies, let-7b in the $\mathrm{SN}[25]$ and let-7e in the anterior cingulate gyri [26] were found to be upregulated in PD patients compared to healthy controls. Moreover, let-7g-3p was upregulated in the CSF of PD patients $[30,35]$. The dysregulation observed for let-7d-5p, let-7f-5p and let-7g were also found to be positively correlated in both the prefrontal cortex and blood leukocytes of PD patients [27]. In contrast, downregulated expressions of let-7a and let-7f were found in the plasma of treatment-naïve PD patients [32].

In animal PD models, let-7f was observed to be upregulated in the striatal tissues of LRRK2-KO mice as compared to control mice [28] while let-7 was reported to be downregulated in an A53T $\alpha$-synuclein-overexpressed model of Caenorhabditis elegans (C. elegans) [40].

Extensive research conducted on let-7 revealed that let-7 members regulate processes such as apoptosis [79,80], immune system modulation [81-86], axon guidance [87] and regeneration [88,89], sleep [90], blood-brain-barrier maintenance [91] and cellular senescence [92]. Li and colleagues (2017) showed that the overexpression of let-7d promoted cell viability while let-7d-KO reduced cell viability in 6-OHDA-treated MN9D cells through the binding of let-7d to the $3^{\prime}$-UTR of caspase-3 mRNA, thus reducing the activity of caspase-3-mediated cell death [79]. In addition, let-7/miR-98 can target the $3^{\prime}$-UTR of Fas and reduce Fas-mediated apoptosis [80]. These evidence suggest that let-7 could be involved in regulating neuronal degeneration in PD. Besides apoptosis, let-7 has been shown to regulate several immune processes. In B cells, the let-7a-1/let-7d/let-7f-1 cluster (let-7adf) specifically inhibits $\mathrm{T}$ cell-independent (TI) antigen-induced immunoglobulin (Ig)M antibody production by reducing glucose and glutamine availability, two principal nutrients important for B cells activation. Jiang et al. (2018) showed that let-7adf can target Hexokinase 2 to suppress glycolysis as well as regulate c-Myc to suppress glutamine uptake, thus demonstrating the adaptive immune role of let-7adf as a metabolic brake on B cell antibody production [81]. Another study showed that the overexpression of let-7c can 
promote macrophage polarization from M1 to M2 phenotype and regulate bactericidal and phagocytic activities of macrophages [82]. let-7 also plays a role in facilitating CD4 T cells anergy [83] as well as the proliferation and differentiation of CD8 T cells [84]. In AD, it has been shown that let-7 is overexpressed and released [85]. Moreover, the extracellular let-7 can act as endogenous damage-associated molecular patterns (DAMPs) and be recognised by TLR7 to promote inflammation and neuronal death [85]. Furthermore, let-7 is able to modulate inflammation by repressing production of cytokines IL- 6 and IL-10 [86]. Let-7 also has PD-specific functions. LRRK2 is able to inhibit let-7 and miR-184* expression, leading to the overexpression of target genes E2F1 and DP, respectively. Since these genes contribute to cell cycle and survival regulation, E2F1/DP dysregulation is important for mediating toxic effects similar to pathogenic LRRK2 such as the degeneration of dopaminergic neurons [93]. In addition, the loss of let-7 can lead to decreased $\alpha$-synuclein expression and accumulation, increased autophagy, increased oxidative stress and increased lipid content in C. elegans [94]. Therefore, the targeting of let-7 or its targets may have therapeutic potential in PD treatment.

\section{4. $m i R-485$}

Little has been discovered about the functions of miR-485. However, this miRNA has been suggested to be dysregulated in PD. In the post-mortem human brain, miR-485-5p was reported to be downregulated in the SN [43] while the complementary strand, miR-485-3p was observed to be upregulated in the putamen tissues [44] of PD patients as compared to healthy controls. Conflicting trends were also observed in the CSF. Gui et al. (2015) reported upregulation of miR-485-5p in the exosomes isolated from the CSF of PD patients [30] while Burgos et al. (2014) showed that miR-485-5p was downregulated in the CSF of PD patients [35]. In the plasma, miR-485-5p was found to be downregulated in PD patients [32,45].

Some miR-485-mediated pathways suggested in the literature include apoptosis [95,96], immune modulation [97,98], iron homeostasis [99] and synaptic plasticity [100]. miR-485-5p can target matrix metalloprotease (MMP)-14 [97], a membrane protein that can promote axon regeneration when inhibited [101]. MMP-14 upregulation is also observed in microglia/macrophages associated with neurodegenerative and neuroinflammatory pathologies both in human biopsies and mouse models [98]. In $\mathrm{AD}$, the expression of MMP-14 was found in reactive astrocytes [102]. These evidences suggest that miR-485 can regulate immune responses through MMP-14. In contrast, conflicting observations were reported for miR-485 in regulating apoptosis. Wang et al. (2018) demonstrated that miR-485 can target Smad ubiquitin regulatory factor 2 (Smurf2) and promote apoptosis through the Smurf2-mediated TGF- $\beta /$ Smads signalling pathway in chronic asthmatic mouse models [95]. However, Chen and colleagues (2016) showed that miR-485-5p is able to target TNF receptor (TNFR)-associated death domain (TRADD) and prevent TNF- $\alpha$-induced neuronal cell apoptosis [96].

Beside apoptosis, miR-485 is also able to target the expression of peroxisome proliferator-activated receptor gamma (PPAR $\gamma$ ) coactivator- $1 \alpha$ (PGC-1 $\alpha$ ) [103]. PGC-1 $\alpha$ can induce the expression of reactive oxygen species (ROS) scavenging enzymes, such as, glutathione peroxidase-1, catalase and superoxide dismutase, to reduce oxidative stress [104]. Moreover, PGC-1 $\alpha$ knockout mice displayed an increased vulnerability to MPTP-induced degeneration of nigral DA neurons [104]. PGC- $1 \alpha$ knockdown also increased $\alpha$-synuclein accumulation in neuronal cells [105], suggesting the neuroprotective role for PGC- $1 \alpha$. Thus, the suppression of PGC- $1 \alpha$ by miR- 485 indicates a neurotoxic function for miR-485 in PD.

\section{5. $m i R-26$}

The miR-26 family consists of miR-26a-1, miR-26a-2 and miR-26b in humans [106]. In the CNS, miR-26a was observed to be upregulated the SN tissues and in the exosomes isolated from the CSF of PD patients as compared to healthy controls [25,30]. In the striatal tissues of rodent PD models, miR-26a upregulation was observed in rotenone-treated rats [47] while miR-26b upregulation was reported in 
LRRK2-KO mice [28]. However, in the PBMCs isolated from PD patients, miR-26a downregulation was detected instead [31].

The role of miR-26 in neurodegenerative diseases has not been well-studied. However, in other disease models, miR-26 has been suggested to modulate processes such as DNA repair $[107,108]$, apoptosis [109,110], autophagy [111,112], LTP maintenance [113], immune regulation [114,115] and glucose and lipids metabolism [116]. miR-26a is able to target phosphatase and tensin homolog on chromosome 10 (PTEN) [107]. PTEN has both protein and lipid phosphatase activity that inhibits the PI3K/AKT pathway involved in cell survival [108]. Thus, overexpression of PTEN may contribute to the activation of proteolytic cascade for apoptosis [117]. In addition, PTEN-induced kinase 1 (PINK1) has been demonstrated to be important in safeguarding mitochondrial function and integrity and mutations in PINK1 have been linked to familial PD [118]. Thus, miR-26 may regulate neurodegeneration in PD through PTEN and PINK1. Besides PTEN, miR-26 can also induce apoptosis and inhibit autophagy by targeting TGF- $\beta$ and suppressing the TGF- $\beta /$ JNK signalling pathway [111]. miR-26 may also modulate the immune system through NF- $\mathrm{KB}$ signalling. miR-26 is able to dampen the induction of cytokines, such as IL-6, by downregulating the TNF- $\alpha / N F-\kappa B$ signalling axis through the silencing of 2 NF- $k B$ signalling factors, HMGA1 and MALT1 [114]. Furthermore, miR-26b can directly target TAK1 and TAB3, the upstream positive regulators of the NF- $k B$ pathway [115]. Thus, these evidence suggest that miR-26 may play a role in suppressing neuroinflammation in PD.

\section{Significance and Challenges of miRNA Research}

We have highlighted several candidate miRNAs that may aggravate or mitigate PD progression through their actions in the CNS or periphery. miRNAs are capable of regulating several signaling pathways as each miRNA can target and bind to an average of 100-200 genes, making them potent modulators of gene expression [119]. Therefore, it is important to uncover the mechanisms of dysregulated miRNAs in diseases as these miRNAs and their targets can have great therapeutic potential in the development of treatments for these diseases. In addition, the presence of dysregulated miRNAs in blood also signal the prospect of using serum/plasma miRNAs as diagnostic markers for diseases. The success of miRNA biomarker research could translate to more accurate disease diagnosis using less invasive methods. This is especially important in neurodegenerative diseases, such as PD, where diagnosis is often given based on symptomatic examinations and cognitive assessments rather than through more objective tests (such as blood tests).

Despite the importance of miRNA research, the literature currently available on the actions of miRNA in PD is greatly lacking. Moreover, results of miRNA studies have not been consistent with each other. There are several potential limitations in published studies. It is difficult to identify clinically important miRNAs in diseases because clinical studies thus far are limited by their small sample size which may not have sufficient power to identify the effect size difference. In addition, the areas investigated also differ in the studies as noted in Table 2. Moreover, the techniques used to characterise the miRNA profile in each study have different sensitivities which can affect the output data obtained. The lack of a standardised protocol in miRNA isolation and detection has led to the identification of non-overlapping and non-replicating sets of potentially dysregulated miRNAs. Factors such as different study designs and experimental conditions, different tissue sources or PD models and the use of PD samples with different sample size, clinical features and pharmacological treatment could all result in discordant results among studies. Therefore, clinical articles published on the same disease may report very different miRNA expression profiles, making it difficult to identify or validate biologically relevant miRNAs.

There are also several challenges in developing miRNA-based therapeutic therapies. One major problem is the delivery of candidate miRNA(s) to specific sites. The development of specific and effective miRNA delivery systems is vital as the delivery vehicle must allow miRNAs to cross the blood-brain barrier. As miRNAs are easily degradable, the delivery systems employed must also be able to stabilise and extend the life of the miRNAs. Furthermore, using miRNAs in treatment may 
be a double-edged sword. While it is advantageous that miRNAs as powerful modulators of gene expression have the ability to alter several signaling pathways at once to switch the cellular physiology from an apoptotic state to one that favors survival, this also means that side effects in unspecific sites could be problematic. Hence, specific and effective delivery systems in miRNA-based therapy are vital. The current experimental approaches used in miRNA research have many limitations. As miRNAs are small and easily degradable, the existing isolation methods can lead to a great loss in yield or a biased recovery of certain miRNAs. This can affect the potential of miRNAs as diagnostic markers for diseases. Moreover, the experimental approaches required for miRNA studies are also very costly. Hence, these challenges could slow down the progression of miRNAs research.

\section{Conclusions}

We have highlighted several miRNAs that show promise in having therapeutic and/or diagnostic potential in PD as well as the pathophysiologic role of miRNAs in disease states. Developing an optimal delivery system and unravelling druggable targets of miRNAs in both experimental and human models and clinical validation of the results may pave the way for novel therapeutics in PD.

Author Contributions: S.Y.G. wrote majority of the review article with inputs from all authors. All authors have contributed to reviewing and revising of the manuscript and approving of the final version. The corresponding authors attest that all listed authors meet authorship criteria and that no others meeting the criteria have been omitted.

Funding: This work was supported by grants from Singapore Ministry of Health's National Medical Research Council (NMRC): NMRC/TA/0044/2015 and NMRC/TCR/013-NNI/2014.

Conflicts of Interest: The authors declare no conflict of interest.

\section{References}

1. De Lau, L.M.; Breteler, M.M. Epidemiology of Parkinson's disease. Lancet Neurol. 2006, 5, 525-535. [CrossRef]

2. Jankovic, J. Parkinson's disease: Clinical features and diagnosis. J. Neurol. Neurosurg. Psychiatry 2008, 79, 368-376. [CrossRef] [PubMed]

3. Hallett, P.J.; Engelender, S.; Isacson, O. Lipid and immune abnormalities causing age-dependent neurodegeneration and Parkinson's disease. J. Neuroinflamm. 2019, 16, 153. [CrossRef] [PubMed]

4. Burke, R.E.; Dauer, W.T.; Vonsattel, J.P. A critical evaluation of the Braak staging scheme for Parkinson's disease. Ann. Neurol. 2008, 64, 485-491. [CrossRef] [PubMed]

5. Giguère, N.; Burke Nanni, S.; Trudeau, L.E. On cell loss and selective vulnerability of neuronal populations in Parkinson's disease. Front. Neurol. 2018, 9, 455. [CrossRef] [PubMed]

6. Stacy, M. Nonmotor symptoms in Parkinson's disease. Int. J. Neurosci. 2011, 121, 9-17. [CrossRef] [PubMed]

7. Hayes, M.T. Parkinson's disease and parkinsonism. Am. J. Med. 2019, 132, 802-807. [CrossRef] [PubMed]

8. Elkouzi, A.; Vedam-Mai, V.; Eisinger, R.S.; Okun, M.S. Emerging therapies in Parkinson disease-Repurposed drugs and new approaches. Nat. Rev. Neurol. 2019, 15, 204-223. [CrossRef] [PubMed]

9. Jankovic, J.; Aguilar, L.G. Current approaches to the treatment of Parkinson's disease. Neuropsychiatr. Dis. Treat. 2008, 4, 743-757. [CrossRef] [PubMed]

10. Grassi, D.; Howard, S.; Zhou, M.; Diaz-Perez, N.; Urban, N.T.; Guerrero-Given, D.; Kamasawa, N.; Volpicelli-Daley, L.A.; LoGrasso, P.; Lasmézas, C.I. Identification of a highly neurotoxic $\alpha$-synuclein species inducing mitochondrial damage and mitophagy in Parkinson's disease. PNAS 2018, 115, E2634-E2643. [CrossRef] [PubMed]

11. Singh, A.; Zhi, L.; Zhang, H. LRRK2 and mitochondria: Recent advances and current views. Brain Res. 2019, 1702, 96-104. [CrossRef] [PubMed]

12. Kortekaas, R.; Leenders, K.L.; van Oostrom, J.C.; Vaalburg, W.; Bart, J.; Willemsen, A.T.; Hendrikse, N.H. Blood-brain barrier dysfunction in Parkinsonian midbrain in vivo. Ann. Neurol. 2005, 57, 176-179. [CrossRef] [PubMed] 
13. Brochard, V.; Combadière, B.; Prigent, A.; Laouar, Y.; Perrin, A.; Beray-Berthat, V.; Bonduelle, O.; Alvarez-Fischer, D.; Callebert, J.; Launay, J.M.; et al. Infiltration of CD4 ${ }^{+}$lymphocytes into the brain contributes to neurodegeneration in a mouse model of Parkinson disease. J. Clin. Investig. 2009, 119, $182-192$. [CrossRef] [PubMed]

14. Heman-Ackah, S.M.; Hallegger, M.; Rao, M.S.; Wood, M.J. RISC in PD: The impact of microRNAs in Parkinson's disease cellular and molecular pathogenesis. Front. Mol. Neurosci. 2013, 6, 40. [CrossRef] [PubMed]

15. Schwarzenbach, H.; Gahan, P.B. MicroRNA shuttle from cell-to-cell by exosomes and its impact in cancer. Noncoding RNA 2019, 5, E28. [CrossRef] [PubMed]

16. Kehl, T.; Backes, C.; Kern, F.; Fehlmann, T.; Ludwig, N.; Meese, E.; Lenhof, H.P.; Keller, A. About miRNAs, miRNA seeds, target genes and target pathways. Oncotarget 2017, 8, 107167-107175. [CrossRef] [PubMed]

17. Lewis, B.P.; Shih, I.H.; Jones-Rhoades, M.W.; Bartel, D.P.; Burge, C.B. Prediction of mammalian microRNA targets. Cell 2003, 115, 787-798. [CrossRef]

18. Griffiths-Jones, S.; Grocock, R.J.; van Dongen, S.; Bateman, A.; Enright, A.J. miRBase: microRNA sequences, targets and gene nomenclature. Nucleic Acids Res. 2006, 34, D140-4. [CrossRef] [PubMed]

19. Gaudet, A.D.; Fonken, L.K.; Watkins, L.R.; Nelson, R.J.; Popovich, P.G. MicroRNAs: Roles in regulating neuroinflammation. Neuroscientist 2018, 24, 221-245. [CrossRef] [PubMed]

20. Leung, A.K.; Sharp, P.A. MicroRNA functions in stress responses. Mol Cell. 2010, 40, 205-215. [CrossRef] [PubMed]

21. Shivdasani, R.A. MicroRNAs: Regulators of gene expression and cell differentiation. Blood 2006, 108, 3646-3653. [CrossRef] [PubMed]

22. Etheridge, A.; Lee, I.; Hood, L.; Galas, D.; Wang, K. Extracellular microRNA: A new source of biomarkers. Mutat. Res. 2011, 717, 85-90. [CrossRef] [PubMed]

23. Kamal, M.A.; Mushtaq, G.; Greig, N.H. Current update on synopsis of miRNA dysregulation in neurological disorders. CNS Neurol. Disord. Drug Targets 2015, 14, 492-501. [CrossRef] [PubMed]

24. Palanichamy, J.K.; Rao, D.S. miRNA dysregulation in cancer: Towards a mechanistic understanding. Front. Genet. 2014, 5, 54. [CrossRef] [PubMed]

25. Briggs, C.E.; Wang, Y.; Kong, B.; Woo, T.U.; Iyer, L.K.; Sonntag, K.C. Midbrain dopamine neurons in Parkinson's disease exhibit a dysregulated miRNA and target-gene network. Brain Res. 2015, 1618, 111-121. [CrossRef] [PubMed]

26. Tatura, R.; Kraus, T.; Giese, A.; Arzberger, T.; Buchholz, M.; Höglinger, G.; Müller, U. Parkinson's disease: SNCA-, PARK2-, and LRRK2-targeting microRNAs elevated in cingulate gyrus. Parkinsonism Relat. Disord. 2016, 33, 115-121. [CrossRef] [PubMed]

27. Chatterjee, P.; Roy, D. Comparative analysis of RNA-Seq data from brain and blood samples of Parkinson's disease. Biochem. Biophys. Res. Commun. 2017, 484, 557-564. [CrossRef] [PubMed]

28. Dorval, V.; Mandemakers, W.; Jolivette, F.; Coudert, L.; Mazroui, R.; De Strooper, B.; Hébert, S.S. Gene and microRNA transcriptome analysis of Parkinson's related LRRK2 mouse models. PLoS ONE 2014, 9, e85510. [CrossRef] [PubMed]

29. He, R.; Xie, X.; Lv, L.; Huang, Y.; Xia, X.; Chen, X.; Zhang, L. Comprehensive investigation of aberrant microRNAs expression in cells culture model of $\mathrm{MnCl}$-induced neurodegenerative disease. Biochem. Biophys. Res. Commun. 2017, 486, 342-348. [CrossRef] [PubMed]

30. Gui, Y.; Liu, H.; Zhang, L.; Lv, W.; Hu, X. Altered microRNA profiles in cerebrospinal fluid exosome in Parkinson disease and Alzheimer disease. Oncotarget 2015, 6, 37043-37053. [CrossRef] [PubMed]

31. Martins, M.; Rosa, A.; Guedes, L.C.; Fonseca, B.V.; Gotovac, K.; Violante, S.; Mestre, T.; Coelho, M.; Rosa, M.M.; Martin, E.R.; et al. Convergence of miRNA expression profiling, $\alpha$-synuclein interaction and GWAS in Parkinson's disease. PLoS ONE 2011, 6, e25443. [CrossRef] [PubMed]

32. Chen, L.; Yang, J.; Lü, J.; Cao, S.; Zhao, Q.; Yu, Z. Identification of aberrant circulating miRNAs in Parkinson's disease plasma samples. Brain Behav. 2018, 8, e00941. [CrossRef] [PubMed]

33. Schwienbacher, C.; Foco, L.; Picard, A.; Corradi, E.; Serafin, A.; Panzer, J.; Zanigni, S.; Blankenburg, H.; Facheris, M.F.; Giannini, G.; et al. Plasma and white blood cells show different miRNA expression profiles in Parkinson's disease. J. Mol. Neurosci. 2017, 62, 244-254. [CrossRef] [PubMed] 
34. Serafin, A.; Foco, L.; Zanigni, S.; Blankenburg, H.; Picard, A.; Zanon, A.; Giannini, G.; Pichler, I.; Facheris, M.F.; Cortelli, P.; et al. Overexpression of blood microRNAs 103a, 30b, and 29a in L-dopa-treated patients with PD. Neurology 2015, 84, 645-653. [CrossRef] [PubMed]

35. Burgos, K.; Malencia, I.; Metpally, R.; Courtright, A.; Rakela, B.; Beach, T.; Shill, H.; Adler, C.; Sabbagh, M.; Villa, S.; et al. Profiles of extracellular miRNA in cerebrospinal fluid and serum from patients with Alzheimer's and Parkinson's disease correlate with disease status and features of pathology. PLoS ONE 2014, 9, e94839. [CrossRef] [PubMed]

36. Lungu, G.; Stoica, G.; Ambrus, A. MicroRNA profiling and the role of microRNA-132 in neurodegeneration using a rat model. Neurosci. Lett. 2013, 553, 153-158. [CrossRef] [PubMed]

37. Ma, W.; Li, Y.; Wang, C.; Xu, F.; Wang, M.; Liu, Y. Serum miR-221 serves as a biomarker for Parkinson's disease. Cell Biochem. Funct. 2016, 34, 511-515. [CrossRef] [PubMed]

38. Botta-Orfila, T.; Morató, X.; Compta, Y.; Lozano, J.J.; Falgàs, N.; Valldeoriola, F.; Pont-Sunyer, C.; Vilas, D.; Mengual, L.; Fernández, M.; et al. Identification of blood serum micro-RNAs associated with idiopathic and LRRK2 Parkinson's disease. J. Neurosci. Res. 2014, 92, 1071-1077. [CrossRef] [PubMed]

39. Margis, R.; Margis, R.; Rieder, C.R. Identification of blood microRNAs associated to Parkinson's disease. J. Biotechnol. 2011, 152, 96-101. [CrossRef] [PubMed]

40. Asikainen, S.; Rudgalvyte, M.; Heikkinen, L.; Louhiranta, K.; Lakso, M.; Wong, G.; Nass, R. Global microRNA expression profiling of Caenorhabditis elegans Parkinson's disease models. J. Mol. Neurosci. 2010, 41, 210-218. [CrossRef] [PubMed]

41. Cao, X.Y.; Lu, J.M.; Zhao, Z.Q.; Li, M.C.; Lu, T.; An, X.S.; Xue, L.J. MicroRNA biomarkers of Parkinson's disease in serum exosome-like microvesicles. Neurosci. Lett. 2017, 644, 94-99. [CrossRef] [PubMed]

42. Rosas-Hernandez, H.; Chigurupati, S.; Raymick, J.; Robinson, B.; Cuevas, E.; Hanig, J.; Sarkar, S. Identification of altered microRNAs in serum of a mouse model of Parkinson's disease. Neurosci. Lett. 2018, 687, 1-9. [CrossRef] [PubMed]

43. Cardo, L.F.; Coto, E.; Ribacoba, R.; Menéndez, M.; Moris, G.; Suárez, E.; Alvarez, V. MiRNA profile in the substantia nigra of Parkinson's disease and healthy subjects. J. Mol. Neurosci. 2014, 54, 830-836. [CrossRef] [PubMed]

44. Nair, V.D.; Ge, Y. Alterations in miRNAs reveal a dysregulated molecular regulatory network in Parkinson's disease striatum. Neurosci. Lett. 2016, 629, 99-104. [CrossRef] [PubMed]

45. Khoo, S.K.; Petillo, D.; Kang, U.J.; Resau, J.H.; Berryhill, B.; Linder, J.; Forsgren, L.; Neuman, L.A.; Tan, A.C. Plasma-based circulating microRNA biomarkers for Parkinson's disease. J. Parkinson's Dis. 2012, 2, 321-331. [CrossRef]

46. Nelson, P.T.; Wang, W.X.; Janse, S.A.; Thompson, K.L. MicroRNA expression patterns in human anterior cingulate and motor cortex: A study of dementia with Lewy bodies cases and controls. Brain Res. 2018, 1678, 374-383. [CrossRef] [PubMed]

47. Horst, C.H.; Schlemmer, F.; de Aguiar Montenegro, N.; Domingues, A.C.M.; Ferreira, G.G.; da Silva Ribeiro, C.Y.; de Andrade, R.R.; Del Bel Guimarães, E.; Titze-de-Almeida, S.S.; Titze-de-Almeida, R. Signature of aberrantly expressed microRNAs in the striatum of rotenone-induced Parkinsonian rats. Neurochem. Res. 2018, 43, 2132-2140. [CrossRef] [PubMed]

48. Ding, H.; Huang, Z.; Chen, M.; Wang, C.; Chen, X.; Chen, J.; Zhang, J. Identification of a panel of five serum miRNAs as a biomarker for Parkinson's disease. Parkinsonism Relat. Disord. 2016, 22, 68-73. [CrossRef] [PubMed]

49. Mo, M.; Xiao, Y.; Huang, S.; Cen, L.; Chen, X.; Zhang, L.; Luo, Q.; Li, S.; Yang, X.; Lin, X.; et al. MicroRNA expressing profiles in A53T mutant alpha-synuclein transgenic mice and Parkinsonian. Oncotarget 2017, 8, 15-28. [CrossRef] [PubMed]

50. Kong, Y.; Liang, X.; Liu, L.; Zhang, D.; Wan, C.; Gan, Z.; Yuan, L. High Throughput Sequencing Identifies MicroRNAs Mediating $\alpha$-Synuclein Toxicity by Targeting Neuroactive-Ligand Receptor Interaction Pathway in Early Stage of Drosophila Parkinson's Disease Model. PLoS ONE 2015, 10, e0137432. [CrossRef] [PubMed]

51. Dong, H.; Wang, C.; Lu, S.; Yu, C.; Huang, L.; Feng, W.; Xu, H.; Chen, X.; Zen, K.; Yan, Q.; et al. A panel of four decreased serum microRNAs as a novel biomarker for early Parkinson's disease. Biomarkers 2016, 21, 129-137. [CrossRef] [PubMed] 
52. Cardo, L.F.; Coto, E.; de Mena, L.; Ribacoba, R.; Moris, G.; Menéndez, M.; Alvarez, V. Profile of microRNAs in the plasma of Parkinson's disease patients and healthy controls. J. Neurol. 2013, 260, 1420-1422. [CrossRef] [PubMed]

53. Marques, T.M.; Kuiperij, H.B.; Bruinsma, I.B.; van Rumund, A.; Aerts, M.B.; Esselink, R.A.J.; Bloem, B.R.; Verbeek, M.M. MicroRNAs in Cerebrospinal Fluid as Potential Biomarkers for Parkinson's Disease and Multiple System Atrophy. Mol. Neurobiol. 2017, 54, 7736-7745. [CrossRef] [PubMed]

54. Sheinerman, K.S.; Toledo, J.B.; Tsivinsky, V.G.; Irwin, D.; Grossman, M.; Weintraub, D.; Hurtig, H.I.; Chen-Plotkin, A.; Wolk, D.A.; McCluskey, L.F.; et al. Circulating brain-enriched microRNAs as novel biomarkers for detection and differentiation of neurodegenerative diseases. Alzheimer's Res. Ther. 2017, 9, 89. [CrossRef] [PubMed]

55. Hoss, A.G.; Labadorf, A.; Beach, T.G.; Latourelle, J.C.; Myers, R.H. microRNA Profiles in Parkinson's Disease Prefrontal Cortex. Front. Aging Neurosci. 2016, 8, 36. [CrossRef] [PubMed]

56. Soreq, L.; Salomonis, N.; Bronstein, M.; Greenberg, D.S.; Israel, Z.; Bergman, H.; Soreq, H. Small RNA sequencing-microarray analyses in Parkinson leukocytes reveal deep brain stimulation-induced splicing changes that classify brain region transcriptomes. Front. Mol. Neurosci. 2013, 6, 10. [CrossRef] [PubMed]

57. Mao, L.; Liu, S.; Hu, L.; Jia, L.; Wang, H.; Guo, M.; Chen, C.; Liu, Y.; Xu, L. miR-30 family: A promising regulator in development and disease. Biomed. Res. Int. 2018, 2018, 9623412. [CrossRef] [PubMed]

58. Li, D.; Yang, H.; Ma, J.; Luo, S.; Chen, S.; Gu, Q. MicroRNA-30e regulates neuroinflammation in MPTP model of Parkinson's disease by targeting Nlrp3. Hum. Cell. 2018, 31, 106-115. [CrossRef] [PubMed]

59. Fan, Y.; Xiao, S. Progression rate associated peripheral blood biomarkers of Parkinson's disease. J. Mol. Neurosci. 2018, 65, 312-318. [CrossRef] [PubMed]

60. Mellios, N.; Huang, H.S.; Grigorenko, A.; Rogaev, E.; Akbarian, S. A set of differentially expressed miRNAs, including miR-30a-5p, act as post-transcriptional inhibitors of BDNF in prefrontal cortex. Hum. Mol. Genet. 2008, 17, 3030-3042. [CrossRef] [PubMed]

61. Hyman, C.; Hofer, M.; Barde, Y.A.; Juhasz, M.; Yancopoulos, G.D.; Squinto, S.P.; Lindsay, R.M. BDNF is a neurotrophic factor for dopaminergic neurons of the substantia nigra. Nature 1991, 350, 230-232. [CrossRef] [PubMed]

62. Levivier, M.; Przedborski, S.; Bencsics, C.; Kang, U.J. Intrastriatal implantation of fibroblasts genetically engineered to produce brain-derived neurotrophic factor prevents degeneration of dopaminergic neurons in a rat model of Parkinson's disease. J. Neurosci. 1995, 15, 7810-7820. [CrossRef] [PubMed]

63. Wang, Y.; Liu, H.; Zhang, B.S.; Soares, J.C.; Zhang, X.Y. Low BDNF is associated with cognitive impairments in patients with Parkinson's disease. Parkinsonism Relat. Disord. 2016, 29, 66-71. [CrossRef] [PubMed]

64. Kriegel, A.J.; Liu, Y.; Fang, Y.; Ding, X.; Liang, M. The miR-29 family: Genomics, cell biology, and relevance to renal and cardiovascular injury. Physiol. Genomics. 2012, 44, 237-244. [CrossRef] [PubMed]

65. Bai, X.; Tang, Y.; Yu, M.; Wu, L.; Liu, F.; Ni, J.; Wang, Z.; Wang, J.; Fei, J.; Wang, W.; et al. Downregulation of blood serum microRNA 29 family in patients with Parkinson's disease. Sci. Rep. 2017, 7, 5411. [CrossRef] [PubMed]

66. Kole, A.J.; Swahari, V.; Hammond, S.M.; Deshmukh, M. miR-29b is activated during neuronal maturation and targets BH3-only genes to restrict apoptosis. Genes Dev. 2011, 25, 125-130. [CrossRef] [PubMed]

67. Roshan, R.; Shridhar, S.; Sarangdhar, M.A.; Banik, A.; Chawla, M.; Garg, M.; Singh, V.P.; Pillai, B. Brain-specific knockdown of miR-29 results in neuronal cell death and ataxia in mice. RNA 2014, 20, 1287-1297. [CrossRef] [PubMed]

68. Cao, L.; Zhang, Y.; Zhang, S.; Jiang, T.P.; Chen, L.; Liu, J.; Zhou, S. MicroRNA-29b alleviates oxygen and glucose deprivation/reperfusion-induced injury via inhibition of the p53-dependent apoptosis pathway in N2a neuroblastoma cells. Exp. Ther. Med. 2018, 15, 67-74. [CrossRef] [PubMed]

69. Xu, S.; Wu, W.; Huang, H.; Huang, R.; Xie, L.; Su, A.; Liu, S.; Zheng, R.; Yuan, Y.; Zheng, H.L.; et al. The p53/miRNAs/Ccna2 pathway serves as a novel regulator of cellular senescence: Complement of the canonical p53/p21 pathway. Aging Cell 2019, 18, e12918. [CrossRef] [PubMed]

70. Martinez, I.; Cazalla, D.; Almstead, L.L.; Steitz, J.A.; DiMaio, D. miR-29 and miR-30 regulate B-Myb expression during cellular senescence. Proc. Natl. Acad. Sci. USA 2011, 108, 522-527. [CrossRef] [PubMed]

71. Papadopoulou, A.S.; Serneels, L.; Achsel, T.; Mandemakers, W.; Callaerts-Vegh, Z.; Dooley, J.; Lau, P.; Ayoubi, T.; Radaelli, E.; Spinazzi, M.; et al. Deficiency of the miR-29a/b-1 cluster leads to ataxic features and cerebellar alterations in mice. Neurobiol. Dis. 2015, 73, 275-288. [CrossRef] [PubMed] 
72. Steiner, D.F.; Thomas, M.F.; Hu, J.K.; Yang, Z.; Babiarz, J.E.; Allen, C.D.; Matloubian, M.; Blelloch, R.; Ansel, K.M. MicroRNA-29 regulates T-box transcription factors and interferon- $\gamma$ production in helper T cells. Immunity 2011, 35, 169-181. [CrossRef] [PubMed]

73. Chandiran, K.; Lawlor, R.; Pannuti, A.; Perez, G.G.; Srinivasan, J.; Golde, T.E.; Miele, L.; Osbourne, B.A.; Minter, L.M. Notch1 primes CD4 T cells for T helper type I differentiation through its early effects on miR-29. Mol. Immunol. 2018, 99, 191-198. [CrossRef] [PubMed]

74. Smith, K.M.; Guerau-de-Arellano, M.; Costinean, S.; Williams, J.L.; Bottoni, A.; Mavrikis Cox, G.; Satoskar, A.R.; Croce, C.M.; Racke, M.K.; Lovett-Racke, A.E.; et al. miR-29ab1 deficiency identifies a negative feedback loop controlling Th1 bias that is dysregulated in multiple sclerosis. J. Immunol. 2012, 189, 1567-1576. [CrossRef] [PubMed]

75. Lyu, G.; Guan, Y.; Zhang, C.; Zong, L.; Sun, L.; Huang, X.; Huang, L.; Zhang, L.; Tian, X.L.; Zhou, Z.; et al. TGF- $\beta$ signalling alters H4K20me3 status via miR-29 and contributes to cellular senescence and cardiac aging. Nat. Commun. 2018, 9, 2560. [CrossRef] [PubMed]

76. Morita, S.; Horii, T.; Kimura, M.; Ochiya, T.; Tajima, S.; Hatada, I. miR-29 represses the activities of DNA methyltransferases and DNA demethylases. Int. J. Mol. Sci. 2013, 14, 14647-14658. [CrossRef] [PubMed]

77. Kustrimovic, N.; Comi, C.; Magistrelli, L.; Rasini, E.; Legnaro, M.; Bombelli, R.; Aleksic, I.; Blandini, F.; Minafra, B.; Riboldazzi, G.; et al. Parkinson's disease patients have a complex phenotypic and functional Th1 bias: Cross-sectional studies of $\mathrm{CD}^{+}{ }^{+}$Th1/Th2/Th17 and Treg in drug naïve and drug-treated patients. J. Neuroinflamm. 2018, 15, 205. [CrossRef] [PubMed]

78. Roush, S.; Slack, F.J. The let-7 family of microRNAs. Trends Cell Biol. 2008, 18, 505-516. [CrossRef] [PubMed]

79. Li, L.; Liu, H.; Song, H.; Qin, Y.; Wang, Y.; Xu, M.; Liu, C.; Gao, J.; Sun, S. Let-7d microRNA attenuates 6-OHDA-induced injury by targeting caspase-3 in MN9D cells. J. Mol. Neurosci. 2017, 63, 403-411. [CrossRef] [PubMed]

80. Wang, S.; Tang, Y.; Cui, H.; Zhao, X.; Luo, X.; Pan, W.; Huang, X.; Shen, N. Let-7/miR-98 regulate Fas and Fas-mediated apoptosis. Genes Immun. 2011, 12, 149-154. [CrossRef] [PubMed]

81. Jiang, S.; Yan, W.; Wang, S.E.; Baltimore, D. Let-7 suppresses B cell activation through restricting the availability of necessary nutrients. Cell Metab. 2018, 27, 393-403. [CrossRef] [PubMed]

82. Banerjee, S.; Xie, N.; Cui, H.; Tan, Z.; Yang, S.; Icyuz, M.; Abraham, E.; Liu, G. MicroRNA let-7c regulates macrophage polarization. J. Immunol. 2013, 190, 6542-6549. [CrossRef] [PubMed]

83. Marcais, A.; Blevins, R.; Graumann, J.; Feytout, A.; Dharmalingam, G.; Carroll, T.; Amado, I.F.; Bruno, L.; Lee, K.; Walzer, T.; et al. microRNA-mediated regulation of mTOR complex components facilitates discrimination between activation and anergy in CD4 T cells. J. Exp. Med. 2014, 211, 2281-2295. [CrossRef] [PubMed]

84. Wells, A.C.; Daniels, K.A.; Angelou, C.C.; Fagerberg, E.; Burnside, A.S.; Markstein, M.; Alfandari, D.; Welsh, R.M.; Pobezinskaya, E.L.; Pobezinsky, L.A. Modulation of let-7 miRNAs controls the differentiation of effector CD8 T cells. ELife 2017, 6, e26398. [CrossRef] [PubMed]

85. Lehmann, S.M.; Krüger, C.; Park, B.; Derkow, K.; Rosenberger, K.; Baumgart, J.; Trimbuch, T.; Eom, G.; Hinz, M.; Kaul, D.; et al. An unconventional role for miRNA: Let-7 activates Toll-like receptor 7 and causes neurodegeneration. Nat. Neurosci. 2012, 15, 827-835. [CrossRef] [PubMed]

86. Schulte, L.N.; Eulalio, A.; Mollenkopf, H.J.; Reinhardt, R.; Vogel, J. Analysis of the host microRNA response to Salmonella uncovers the control of major cytokines by the let-7 family. EMBO J. 2011, 30, 1977-1989. [CrossRef] [PubMed]

87. Wang, X.; Chen, Q.; Yi, S.; Liu, Q.; Zhang, R.; Wang, P.; Qian, T.; Li, S. The microRNAs let-7 and miR-9 down-regulate the axon-guidnace genes $\mathrm{Ntn} 1$ and $\mathrm{Dcc}$ during peripheral nerve regeneration. J. Biol. Chem. 2019, 294, 3489-3500. [CrossRef] [PubMed]

88. Wang, X.W.; Li, Q.; Liu, C.M.; Hall, P.A.; Jiang, J.J.; Katchis, C.D.; Kang, S.; Dong, B.C.; Li, S.; Zhou, F.Q. Lin28 signaling supports mammalian PNS and CNS axon regeneration. Cell Rep. 2018, 24, 2540-2552. [CrossRef] [PubMed]

89. Li, S.; Wang, X.; Gu, Y.; Chen, C.; Wang, Y.; Liu, J.; Hu, W.; Yu, B.; Wang, Y.; Ding, F.; et al. Let-7 microRNAs regenerate peripheral nerve regeneration by targeting nerve growth factor. Mol. Ther. 2015, 23, 423-433. [CrossRef] [PubMed] 
90. Sinigaglia, K.; Wiatrek, D.; Khan, A.; Michalik, D.; Sambrani, N.; Sedmík, J.; Vukić, D.; O'Connell, M.A.; Keegan, L.P. ADAR RNA editing in innate immune response phasing, in circadian clocks and in sleep. Biochim. Biophys. Acta Gene Regul. Mech. 2019, 1862, 356-369. [CrossRef] [PubMed]

91. Rom, S.; Dykstra, H.; Zuluaga-Ramirez, V.; Reichenbach, N.L.; Persidsky, Y. miR-98 and let-7g* protect the blood-brain barrier under neuroinflammatory conditions. J. Cereb. Blood Flow Metab. 2015, 35, 1957-1965. [CrossRef] [PubMed]

92. Benhamed, M.; Herbig, U.; Ye, T.; Dejean, A.; Bischof, O. Senescence is an endogenous trigger for microRNA-directed transcriptional gene silencing in human cells. Nat. Cell Biol. 2012, 14, 266-275. [CrossRef] [PubMed]

93. Gehrke, S.; Imai, Y.; Sokol, N.; Lu, B. Pathogenic LRRK2 negatively regulates microRNA-mediated translational repression. Nature 2010, 466, 637-641. [CrossRef] [PubMed]

94. Shamsuzzama, K.L.; Nazir, A. Modulation of alpha-synuclein expression and associated effects by microRNA let-7 in transgenic C. elegans. Front. Mol. Neurosci. 2017, 10, 328. [CrossRef] [PubMed]

95. Wang, J.; Li, H.Y.; Wang, H.S.; Su, Z.B. MicroRNA-485 modulates the TGF- $\beta /$ Smads signaling pathway in chronic asthmatic mice by targeting Smurf2. Cell Physiol. Biochem. 2018, 51, 692-710. [CrossRef] [PubMed]

96. Chen, Z.; Zhang, Z.; Zhang, D.; Li, H.; Sun, Z. Hydrogen sulfide protects against TNF- $\alpha$ induced neuronal cell apoptosis through miR-485-5p/TRADD signaling. Biochem. Biophys. Res. Commun. 2016, 478, 1304-1309. [CrossRef] [PubMed]

97. Liu, K.; Liu, J.; Bo, Q.F. MFI2-AS1 regulates the aggressive phenotypes in glioma by modulating MMP14 via a positive feedback loop. Eur. Rev. Med. Pharmacol. Sci. 2019, 23, 5884-5895. [CrossRef] [PubMed]

98. Langenfurth, A.; Rinnenthal, J.L.; Vinnakota, K.; Prinz, V.; Carlo, A.S.; Stadelmann, C.; Siffrin, V.; Peaschke, S.; Endres, M.; Heppner, F.; et al. Membrane-type 1 metalloproteinase is upregulated in microglia/brain macrophages in neurodegenerative and neuroinflammatory diseases. J. Neurosci. Res. 2014, 92, 275-286. [CrossRef] [PubMed]

99. Sangokoya, C.; Doss, J.F.; Chi, J.T. Iron-responsive miR-485-3p regulates cellular iron homeostasis by targeting ferroportin. PLoS Genet. 2013, 9, e1003408. [CrossRef] [PubMed]

100. Cohen, J.E.; Lee, P.R.; Chen, S.; Li, W.; Fields, R.D. MicroRNA regulation of homeostatic synaptic plasticity. PNAS 2011, 108, 11650-11655. [CrossRef] [PubMed]

101. Nishihara, T.; Remacle, A.G.; Angert, M.; Shubayev, I.; Shiryaev, S.A.; Liu, H.; Dolkas, J.; Chernov, A.V.; Strongin, A.Y.; Shubayev, V.I. Matrix metalloproteinase-14 both sheds cell surface neuronal glial antigen 2 (NG2) proteoglycan on macrophages and governs the response to peripheral nerve injury. J. Biol. Chem. 2015, 290, 3693-3707. [CrossRef] [PubMed]

102. Liao, M.C.; Van Nostrand, W.E. Degradation of soluble and fibrillar amyloid beta-protein by matrix metalloproteinase (MT1-MMP) in vitro. Biochemistry 2010, 49, 1127-1136. [CrossRef] [PubMed]

103. Lou, C.; Xiao, M.; Cheng, S.; Lu, X.; Jia, S.; Ren, Y.; Li, Z. MiR-485-3p and miR-485-5p suppress breast cancer cell metastasis by inhibiting PGC-1 $\alpha$ expression. Cell Death Dis. 2016, 7, e2159. [CrossRef] [PubMed]

104. St-Pierre, J.; Drori, S.; Uldry, M.; Silvaggi, J.M.; Rhee, J.; Jäger, S.; Handschin, C.; Zheng, K.; Lin, J.; Yang, W.; et al. Suppression of reactive oxygen species and neurodegeneration by the PGC-1 transcriptional coactivators. Cell 2006, 127, 397-408. [CrossRef] [PubMed]

105. Ebrahim, A.S.; Ko, L.W.; Yen, S.H. Reduced expression of peroxisome-proliferator activated receptor gamma coactivator-1alpha enhances alpha-synuclein oligomerization and down regulates AKT/GSK3 $\beta$ signaling pathway in human neuronal cells that inducibly express alpha-synuclein. Neurosci. Lett. 2010, 473, 120-125. [CrossRef] [PubMed]

106. Icli, B.; Dorbala, P.; Feinberg, M.W. An emerging role for the miR-26 family in cardiovascular disease. Trends Cardiovasc. Med. 2014, 24, 241-248. [CrossRef] [PubMed]

107. Huse, J.T.; Brennan, C.; Hambardzumyan, D.; Wee, B.; Pena, J.; Rouhanifard, S.H.; Sohn-Lee, C.; le Sage, C.; Agami, R.; Tuschl, T.; et al. The PTEN-regulating microRNA miR-26a is amplified in high-grade glioma and facilitates gliomagenesis in vivo. Genes Dev. 2009, 23, 1327-1337. [CrossRef] [PubMed]

108. Ogino, M.; Ichimura, M.; Nakano, N.; Minami, A.; Kitagishi, Y.; Matsuda, S. Roles of PTEN with DNA repair in Parkinson's disease. Int. J. Mol. Sci. 2016, 17, E954. [CrossRef] [PubMed]

109. Absalon, S.; Kochanek, D.M.; Raghavan, V.; Krichevsky, A.M. MiR-26b, upregulated in Alzheimer's disease, activates cell cycle entry, tau-phosphorylation, and apoptosis in postmitotic neurons. J. Neurosci. 2013, 33, 14645-14659. [CrossRef] [PubMed] 
110. Chu, T.; Shu, Y.; Qu, Y.; Gao, S.; Zhang, L. miR-26b inhibits total neurite outgrowth, promotes cells apoptosis and downregulates neprilysin in Alzheimer's disease. Int. J. Clin. Exp. Pathol. 2018, 11, 3383-3390.

111. He, Y.; Liu, H.; Jiang, L.; Rui, B.; Mei, J.; Xiao, H. miR-26 induces apoptosis and inhibits autophagy in non-small cell lung cancer cells by suppressing TGF- $\beta 1-J N K$ signaling pathway. Front. Pharmacol. 2019, 9, 1509. [CrossRef] [PubMed]

112. Jin, F.; Wang, Y.; Li, M.; Zhu, Y.; Liang, H.; Wang, C.; Wang, F.; Zhang, C.Y.; Zen, K.; Li, L. MiR-26 enhances chemosensitivity and promotes apoptosis of hepatocellular carcinoma cells through inhibiting autophagy. Cell Death Dis. 2017, 8, e2540. [CrossRef] [PubMed]

113. Gu, Q.H.; Yu, D.; Hu, Z.; Liu, X.; Yang, Y.; Luo, Y.; Zhu, J.; Li, Z. miR-26a and miR-384-5p are required for LTP maintenance and spine enlargement. Nat. Commun. 2015, 6, 6789. [CrossRef] [PubMed]

114. Chen, C.Y.; Chang, J.T.; Ho, Y.F.; Shyu, A.B. MiR-26 down-regulates TNF- $\alpha /$ NF- $\mathrm{kB}$ signalling and IL-6 expression by silencing HMGA1 and MALT1. Nucleic Acids Res. 2016, 44, 3772-3787. [CrossRef] [PubMed]

115. Zhao, N.; Wang, R.; Zhou, L.; Zhu, Y.; Gong, J.; Zhuang, S.M. MicroRNA-26b suppresses the NF-kB signaling and enhances the chemosensitivity of hepatocellular carcinoma cells by targeting TAK1 and TAB3. Mol. Cancer 2014, 13, 35. [CrossRef] [PubMed]

116. Fu, X.; Dong, B.; Tian, Y.; Lefebvre, P.; Meng, Z.; Wang, X.; Pattou, F.; Han, W.; Wang, X.; Lou, F.; et al. MicroRNA-26a regulates insulin sensitivity and metabolism of glucose and lipids. J. Clin. Investig. 2015, 125, 2497-2509. [CrossRef] [PubMed]

117. Wen, S.; Stolarov, J.; Myers, M.P.; Su, J.D.; Wigler, M.H.; Tonks, N.K.; Durden, D.L. PTEN controls tumor-induced angiogenesis. PNAS 2001, 98, 4622-4627. [CrossRef] [PubMed]

118. Pickrell, A.M.; Youle, R.J. The roles of PINK1, parkin, and mitochondrial fidelity in Parkinson's disease. Neuron 2015, 85, 257-273. [CrossRef] [PubMed]

119. Gennarino, V.A.; Sardiello, M.; Mutarelli, M.; Dharmalingam, G.; Maselli, V.; Lago, G.; Banfi, S. HOCTAR database: A unique resource for microRNA target prediction. Gene 2011, 480, 51-58. [CrossRef] [PubMed]

(C) 2019 by the authors. Licensee MDPI, Basel, Switzerland. This article is an open access article distributed under the terms and conditions of the Creative Commons Attribution (CC BY) license (http://creativecommons.org/licenses/by/4.0/). 